\title{
Evaluation of 22 Precipitation and 23 Soil Moisture Products over a Semiarid Area in Southeastern Arizona*
}

\author{
SUSAN STILLMAN AND XUBIN ZENG \\ Department of Atmospheric Sciences, The University of Arizona, Tucson, Arizona \\ Michael G. BOSILOVICH \\ Global Modeling and Assimilation Office, NASA Goddard Space Flight Center, Greenbelt, Maryland
}

(Manuscript received 5 January 2015, in final form 20 August 2015)

\begin{abstract}
Precipitation and soil moisture are rigorously measured or estimated from a variety of sources. Here, 22 precipitation and 23 soil moisture products are evaluated against long-term daily observed precipitation (Pobs) and July-September daily observationally constrained soil moisture (SM) datasets over a densely monitored $150 \mathrm{~km}^{2}$ watershed in southeastern Arizona, United States. Gauge-radar precipitation products perform best, followed by reanalysis and satellite products, and the median correlations of annual precipitation from these three categories with Pobs are 0.83, 0.68, and 0.46, respectively. Precipitation results from phase 5 of the Coupled Model Intercomparison Project (CMIP5) are the worst, including an overestimate of cold season precipitation and a lack of significant correlation of annual precipitation with Pobs from all (except one) models. Satellite soil moisture products perform best, followed by land data assimilation systems and reanalyses, and the CMIP5 results are the worst. For instance, the median unbiased root-meansquare difference (RMSD) values of July-September soil moisture compared with SM are 0.0070, 0.011, 0.014 , and $0.029 \mathrm{~m}^{3} \mathrm{~m}^{-3}$ for these four product categories, respectively. All 17 (except 3) precipitation [17 (except 2) soil moisture] products with at least 20 years of data agree with Pobs (SM) without significant trends. The uncertainties associated with the scale mismatch between Pobs and coarser-resolution products are addressed using two 4-km gauge-radar precipitation products, and their impact on the results presented in this study is overall small. These results identify strengths and weaknesses of each product for future improvement; they also emphasize the importance of using multiple gauge-radar and satellite products along with their uncertainties in evaluating reanalyses and models.
\end{abstract}

\section{Introduction}

Precipitation is the driving force of the terrestrial water cycle and is implicative of the general circulation and is therefore monitored rigorously using a variety of instruments and models. It is measured with high temporal resolution with the greatest accuracy using rain

\footnotetext{
* Supplemental information related to this paper is available at the Journals Online website: http://dx.doi.org/10.1175/JHM-D-150007.s1.

Corresponding author address: Susan Stillman, Department of Atmospheric Sciences, The University of Arizona, PhysicsAtmospheric Sciences Bldg., Rm. 542, 1118 E. 4th St., P.O. Box 210081, Tucson, AZ 85721-0081.

E-mail: sstill88@email.arizona.edu
}

gauges. However, they only represent precipitation at sporadically distributed points, and even the best measurements have uncertainty. Wind has a nonlinear effect on precipitation measurement uncertainties that are a function of rainfall rate and drop size distribution (Habib et al. 1999). Devine and Mekis (2008) found errors of up to nearly $5 \%$ in a study of the performance of several rain gauges. Based on rain measurements from three different types of gauges during 67 storms, Chang and Flannery (1998) found that there were discrepancies of a few percent between each of the gauges and they all recorded over $10 \%$ less rain than the reference gauge. Radar is used to estimate precipitation intensity over intermediate areas with high temporal resolution, but it has the downfall of being inferred from remotely sensed data, as opposed to directly measured, and is influenced by blockages in its direct line of sight so 
topography reduces the areal coverage (e.g., over the western United States).

Alternatively, satellites estimate precipitation globally, but cannot resolve microscale variability and have less frequent measurements (due to over flight cycles in the orbit) and larger errors associated with the indirectness of their measurement techniques. The performance of satellite-based precipitation estimation has been extensively analyzed against gauges at watershed scales through continental scales. Most commonly, satellite-based products are evaluated against gauge data in highly instrumented regions (Bitew et al. 2012; Jiang et al. 2012; J. Liu et al. 2012; Stampoulis and Anagnostou 2012). Gao and Liu (2013) found that four multisatellite precipitation products overall performed better in humid regions than in arid regions and overestimated light rainfall while underestimating moderate and heavy rainfall.

Reanalyses combine model forecast with observations to provide globally continuous fields of the analyzed observations and other variables derived from the background model. While observationally driven, their ability to estimate physical processes, such as precipitation, depends on many factors, including observational coverage and model performance, and is therefore location specific. Bosilovich et al. (2008) evaluated the performance of various reanalysis products over different regions of the globe against gaugesatellite merged products and discussed the uncertainty in the merged products used for evaluation over large space and time scales. Bosilovich (2013) found that several reanalyses reproduced the interannual variability of summer precipitation well over much of the United States, including the southwestern United States [encompassing WGEW (see appendix for acronym expansions)] with correlation coefficients between 0.7 and 0.8 with observations, although mean biases exist throughout the United States. Decker et al. (2012) found that ERA-Interim estimates 6-h precipitation variability better than various other reanalyses and that ERA-40 has the lowest bias.

Precipitation output is also available from weather forecasting and climate models with different spatial resolutions. Because observational data are not used in the time integration, the model results are expected to have larger uncertainties compared with the above products and are not designed to resolve individual events. In particular, precipitation output is available from many different climate models involved in CMIP. While improvements have been made in simulating precipitation characteristics compared with observations during the historical period between the earlier phase 3 and the more recent phase 5 of the Coupled
Model Intercomparison Project (CMIP 3 and CMIP5, respectively), the uncertainty is still high (Sillmann et al. 2013; Geil et al. 2013).

Soil moisture is another major component of the terrestrial water cycle and is driven by precipitation. It helps regulate the surface energy balance by affecting the partitioning of available energy flux into latent and sensible heat fluxes at the surface, particularly in moisture-limited regions. Gravimetric measurement is the most accurate way to measure soil moisture, but this only represents a point location. Furthermore, because of its time-consuming nature, samples are rarely taken with good temporal resolution. In situ soil moisture probes also estimate soil moisture at a point but with better measurement frequency. However, they infer soil moisture indirectly as a function of soil dielectric properties and therefore have greater uncertainty than gravimetric measurements (Ventura et al. 2010). More recently, soil moisture at a spatial scale of several hundred meters and with a depth of $10-50 \mathrm{~cm}$ has been reliably measured using cosmic-ray neutrons (Zreda et al. 2012).

Satellite remote sensing can also estimate soil moisture over large areas, but it has coarser spatial resolutions and its accuracy is affected by various factors, including contamination by radio-frequency interference, particularly in urban areas. De Jeu et al. (2008) explained the uncertainties associated with dense vegetation, nonlinearity of brightness temperature conversion at low soil moisture values, radio-frequency interference, and discrepancies between retrieved soil moisture at differing bands. They also showed that AMSR-E performs poorly over densely vegetated areas and deserts. The SMAP satellite, launched in January 2015, provides three operational products, with efforts to mitigate RFI (Entekhabi et al. 2010): a 3-km radarbased product, a $36-\mathrm{km}$ passive radiometer product, and a 9-km combined radar-radiometer product. Sentinel-1 is expected to provide global 100-m-resolution soil moisture with exact repetition every 6 days, leading to $\sim 1-$ 6 days between measurements in any location (Torres et al. 2012).

Furthermore, soil moisture data are available from reanalyses and LDAS. LDAS has uncoupled land surface schemes that assimilate multiple observations using optimal interpolation and other techniques in near-real time. These merged products produce the best spatial coverage and temporal resolution but have drawbacks such as inaccurately accounting for the uncertainty of each product, unbalanced energy and moisture fluxes, and poorer representation in regions with fewer ground measurements. Additionally, if all available products are used, the highest possible accuracy can be obtained; 
however, changed accuracy over time (as measurements are added or removed) may contribute to falsely perceived trends.

Despite extensive publications as reviewed above, there is still a lack of comprehensive evaluations of upto-date global and continental precipitation and soil moisture products from various sources using highaccuracy surface measurements over a large enough area for a long period of time. WGEW, a $150-\mathrm{km}^{2}$ region in southeastern Arizona, has been used previously to validate various remotely sensed products (Jackson et al. 1993; Ryu et al. 2010; Amitai et al. 2012). In this study, the WGEW rain gauge network with up to 88 gauges [observed precipitation (Pobs)] is used as the ground truth precipitation for comparison with 22 precipitation products. Additionally, 20 soil moisture products are evaluated against the observationally constrained soil moisture of Stillman et al. (2014) over WGEW (SM; described in section 2b). Measurements of such high quality and density are limited to just a few small areas, making WGEW an ideal location for this analysis. In this moisture-limited area where runoff accounts for only a small portion of the precipitation, precipitation and soil moisture are the two most important components of the water cycle, which influence the growth of local vegetation and surface energy and moisture fluxes. The purpose of this study is to determine how well each of the products represents precipitation and soil moisture over WGEW. With over 40 products being evaluated using 58 years of data, this work gives insight into the strengths and weaknesses of product multitude of measurement techniques, algorithms, and models.

Section 2 briefly describes all of the products and the evaluation metrics. Sections 3 and 4 compare precipitation and soil moisture products. Section 5 quantifies uncertainties associated with the horizontal scale mismatch between the WGEW precipitation data and various products, while section 6 provides the conclusions.

\section{Description of precipitation and soil moisture products and evaluation metrics}

\section{a. Precipitation products}

In this evaluation, 22 precipitation products from various sources are compared with daily average precipitation in WGEW (i.e., Pobs). The WGEW rain gauge network, developed and maintained by the USDA-ARS, began collecting data in 1953, and by 1956 many more gauges had been added to the network (Goodrich et al. 2008; Stillman et al. 2013). Since 1953, precipitation has been continuously measured using up to 88 gauges with 1-min frequency over WGEW. Pobs is a 58-yr (1956-2013) daily precipitation product that is calculated as the average of the daily precipitation at all available rain gauges. The watershed is $150 \mathrm{~km}^{2}$, making it one of the densest rain gauge networks with an area greater than $10 \mathrm{~km}^{2}$. This area is still relatively small compared with the resolution of the products being evaluated, and therefore some uncertainty is expected in the evaluation. This scale mismatch will be addressed and the associated uncertainty will be quantified in section 5 .

The 22 precipitation products evaluated here are summarized in Table 1 . They are split into four categories: gauge-radar based (including merged products), satellite based, modeled, and reanalysis. Each product is assigned a number in the first column of Table 1, which is used to represent the product in figures and in discussions below. The temporal and spatial resolutions as well as the data period of each product in Table 1 as used in this analysis do not necessarily represent the original resolutions or the whole period with available data. In most cases, we use the highest temporal resolution available on the archive for each product unless the resolution is subdaily, in which case the resolution closest to daily is used.

Products 1-4 are based entirely on gauge information from a variety of sources. There are some overlaps in the data sources, but each product has a different interpolation scheme and combination of sources. CPC (1) includes gauge data from first-order WMO GTS sites, RFC reports, HADS, and SNOTEL. PREC/L (2) data obtain measurements from gauges in the GHCN2 and CAMS datasets. The University of Delaware (3) precipitation is taken from GHCN, version 2, and the gauges of Legates and Willmott (1990). PRISM (4) includes gauges from many sources including COOP, SNOTEL, Snowcourse, RAWS, CDEC, Agrimet, and EC. Stage IV (5) hourly precipitation combines data from the 12 RFCs that merge gauge and radar precipitation. GPCP (6) is also a merged product that combines satellite (GPI, OPI, SSM/I, TOVS, and AIRS) with gauge (GHCN, CAMS, and GPCC) precipitation and is included here in the gauge-radar category (even though it could also be included in the satellite category).

TRMM (7) represents version 7 of the post-real-time 3B42 precipitation product. While the real-time product only uses satellite-derived precipitation, the post-real-time product incorporates gauge measurements. TRMM (7) includes the passive microwave data from polar-orbiting satellites (TMI, SSM/I, AMSR-E, and AMSU-B), IR data from geosynchronous satellites (CPC merged IR), TRMM Precipitation Radar data, and gauge precipitation from GPCP and CAMS. 
TABLE 1. Precipitation products used in this study.

\begin{tabular}{|c|c|c|c|c|}
\hline No. & Product (producer) & Spatial resolution & Temporal resolution & Reference \\
\hline \multicolumn{5}{|c|}{ Observation } \\
\hline & Pobs (USDA) & $150 \mathrm{~km}^{2}$ & Daily, 1956-2013 & Goodrich et al. (2008) \\
\hline \multicolumn{5}{|c|}{ Gauge-radar } \\
\hline 1 & CPC (NOAA) & $0.25^{\circ}, \mathrm{CONUS}$ & Daily, 1948-2006 & Higgins et al. (2000) \\
\hline 2 & PREC/L (NOAA) & $0.5^{\circ}$, global & Monthly, 1948-2012 & Chen et al. (2002) \\
\hline 3 & University of Delaware & $0.5^{\circ}$, global & Monthly, 1900-2008 & Matsuura and Willmott (2012) \\
\hline 4 & PRISM (Oregon State University) & $4 \mathrm{~km}$, CONUS & Monthly, 1956-2011 & Daly et al. (1994) \\
\hline 5 & Stage IV (NCEP) & $4 \mathrm{~km}$, CONUS & Hourly, 2002-09 & Lin and Mitchell (2005) \\
\hline 6 & GPCP, version 1.2 (NASA) & $1^{\circ}$, global & Daily, 1997-2013 & Huffman et al. (2001) \\
\hline \multicolumn{5}{|c|}{ Satellite } \\
\hline 7 & TRMM 3B42, version 7 (NASA) & $0.25^{\circ}, 50^{\circ} \mathrm{N}-50^{\circ} \mathrm{S}$ & 3-hourly, 1998-2013 & Huffman et al. (2007) \\
\hline 8 & $\begin{array}{l}\text { PERSIANN (University } \\
\text { of California, Irvine) }\end{array}$ & $0.25^{\circ}$, global & Daily, 2000-13 & Sorooshian et al. (2000) \\
\hline 9 & CMORPH (NOAA) & $8 \mathrm{~km}, 60^{\circ} \mathrm{N}-60^{\circ} \mathrm{S}$ & Hourly, 1998-2008 & Joyce et al. (2004) \\
\hline \multicolumn{5}{|c|}{ Model } \\
\hline 10 & HadGEM2-ES (Met Office) & $1.875^{\circ} \times 1.25^{\circ}$, global & Daily, 1948-2003 & Jones et al. (2011) \\
\hline 11 & GFDL CM3 (NOAA) & $200 \mathrm{~km}$, global & Daily, 1949-2004 & Donner et al. (2011) \\
\hline 12 & MIROC5 (Japan) & $1.4^{\circ}$, global & Daily, 1949-2009 & Watanabe et al. (2010) \\
\hline 13 & CCSM, version 4 (NCAR) & $1.25^{\circ} \times 0.9^{\circ}$, global & Daily, 1920-2005 & Gent et al. (2011) \\
\hline 14 & CESM, version 1 (CAM5) (NCAR) & $1.25^{\circ} \times 0.9^{\circ}$, global & Daily, 1920-2005 & X. Liu et al. (2012) \\
\hline 15 & $\begin{array}{l}\text { CESM, version } 1 \text { (with FASTCHEM) } \\
\text { (NCAR) }\end{array}$ & $1.25^{\circ} \times 0.9^{\circ}$, global & Daily, 1920-2005 & Lamarque et al. (2012) \\
\hline 16 & CESM, version 1 (BGC) (NCAR) & $1.25^{\circ} \times 0.9^{\circ}$, global & Daily, 1920-2005 & Moore et al. (2013) \\
\hline \multicolumn{5}{|c|}{ Reanalysis } \\
\hline 17 & MERRA (NASA) & $1 / 2^{\circ} \times 2 / 3^{\circ}$, global & Daily, 1979-2013 & Rienecker et al. (2011) \\
\hline 18 & MERRA-Land (NASA) & $1 / 2^{\circ} \times 2 / 3^{\circ}$, global & Daily, 1981-2013 & Reichle et al. (2011) \\
\hline 19 & ERA-Interim (ECMWF) & $79 \mathrm{~km}$, global & 6-hourly, 1979-2013 & Dee et al. (2011) \\
\hline 20 & CFSR (NOAA) & $38 \mathrm{~km}$, global & 6-hourly, 1979-2010 & Saha et al. (2010) \\
\hline 21 & JRA-55 (Japan) & $60 \mathrm{~km}$, global & Monthly, 1958-2013 & Ebita et al. (2011) \\
\hline 22 & NARR (NOAA) & $32 \mathrm{~km}$, CONUS & Daily, 1979-2013 & Mesinger et al. (2006) \\
\hline
\end{tabular}

PERSIANN (8) relies on the IR data from a network of geosynchronous satellites (GOES-8 and -10, GMS, and Meteosat-6 and -7) with high temporal resolution trained with polar-orbiting satellite microwave data (TMI, SSM/I, AMSR-E, NOAA weather satellites, and DMSP weather satellites) when it becomes available using an artificial neural network algorithm. CMORPH (9) also uses satellite IR (Meteosat-5 and -7, GOES, GMS-5) and passive microwave data (AMSU-B, SSM/I, and TMI), in which precipitation information is derived from microwave brightness temperature and the propagation of microwave-derived precipitation is predicted by satellite IR data. Additionally, CMORPH (9) is bias corrected using CPC precipitation over land and GPCP precipitation over ocean. Note that while the versions of TRMM (7) and CMORPH (9) shown here are gaugesatellite merged products, PERSIANN (8) is a satelliteonly product. The pure satellite versions of CMORPH and TRMM slightly outperform PERSIANN overall, while PERSIANN (8) performs best in the wintertime (see Fig. S1 in the supplemental material).

The models (10-16) used in this analysis are representative of the large number of CMIP5 models that were used in the IPCC AR5. All model products in this analysis are from the first member of its ensemble (r1i1p1). Finally, the reanalyses (17-22) include several of the most recent reanalyses. MERRA-Land (18) is included in this category, but it actually incorporates GPCP pentad gauge-satellite-based precipitation to adjust the hourly MERRA precipitation. Additionally, while the other reanalyses use model-derived precipitation, NARR (22) assimilates gauge precipitation, including PRISM and CMAP data.

\section{b. Soil moisture products}

In addition to the 88 rain gauges in WGEW, there are also 19 in situ soil moisture probes that were installed in 2002 (Keefer et al. 2008). To evaluate products prior to 2002, the observationally constrained soil moisture product over WGEW of Stillman et al. (2014) is used (i.e., SM). This consists of daily summer (JulySeptember) soil moisture inferred from precipitation at 88 rain gauges and is calibrated so that, on average, the daily soil moisture at the gauges collocated with the 19 probes have the highest correlation and lowest rootmean-square difference (RMSD) compared with the 
TABLE 2. Soil moisture products used in this study.

\begin{tabular}{|c|c|c|c|c|c|}
\hline No. & Product (producer) & Spatial resolution & Sensor depth & Temporal resolution & Reference \\
\hline \multicolumn{6}{|c|}{ Observation } \\
\hline & SM & $150 \mathrm{~km}^{2}$ & $0-7.5 \mathrm{~cm}$ & Daily, 1956-2013 & Stillman et al. (2014) \\
\hline \multicolumn{6}{|c|}{ Satellite } \\
\hline 1 & Aquarius (NASA) & $1^{\circ}$, global & Surface & Daily, 2011-13 & Le Vine et al. (2007) \\
\hline 2 & AMSR-E (NASA) & $25 \mathrm{~km}$, global & Surface & Daily, 2002-05 & Njoku et al. (2003) \\
\hline 3 & AMSR-E LPRM (VUA-NASA) & $0.25^{\circ}$, global & Surface & Daily, 2002-06 & Owe et al. (2008) \\
\hline 4 & TRMM LPRM (VUA-NASA) & $0.25^{\circ}$, global & Surface & Daily, 1998-2013 & Owe et al. (2008) \\
\hline 5 & SMOS (European Space Agency) & $40 \mathrm{~km}$, global & Surface & Daily, 2010-13 & Kerr et al. (2001) \\
\hline 6 & ASCAT (European Space Agency) & $25 \mathrm{~km}$, global & Surface & Daily, 2007-13 & Bartalis et al. (2007) \\
\hline \multicolumn{6}{|c|}{ Model } \\
\hline 7 & GFDL CM3 (NOAA) & $2^{\circ} \times 2.5^{\circ}$, global & $1-4 \mathrm{~cm}$ & Monthly, 1955-2004 & Donner et al. (2011) \\
\hline 8 & MIROC5 (Japan) & $1.4^{\circ}$, global & $0-2.5 \mathrm{~cm}$ & Monthly, 1850-2012 & Watanabe et al. (2010) \\
\hline 9 & CCSM, version 4 (NCAR) & $1.25^{\circ} \times 0.9^{\circ}$, global & $2.8-6.2 \mathrm{~cm}$ & Monthly, 1950-2005 & Gent et al. (2011) \\
\hline 10 & CESM, version 1 (CAM5) (NCAR) & $1.25^{\circ} \times 0.9^{\circ}$, global & $2.8-6.2 \mathrm{~cm}$ & Monthly, 1950-2005 & X. Liu et al. (2012) \\
\hline 11 & $\begin{array}{l}\text { CESM, version } 1 \text { (with } \\
\text { FASTCHEM) (NCAR) }\end{array}$ & $1.25^{\circ} \times 0.9^{\circ}$, global & $2.8-6.2 \mathrm{~cm}$ & Monthly, 1950-2005 & Lamarque et al. (2012) \\
\hline 12 & CESM, version 1 (BGC) (NCAR) & $1.25^{\circ} \times 0.9^{\circ}$, global & $2.8-6.2 \mathrm{~cm}$ & Monthly, 1950-2005 & Moore et al. (2013) \\
\hline 13 & HadCM3 (Met Office) & $2.5^{\circ} \times 3.75^{\circ}$, global & $0-5 \mathrm{~cm}$ & Monthly, 1959-2005 & Johns et al. (2003) \\
\hline 14 & HadGEM2-ES (Met Office) & $1.875^{\circ} \times 1.25^{\circ}$, global & $0-5 \mathrm{~cm}$ & Monthly, 1959-2005 & Jones et al. (2011) \\
\hline \multicolumn{6}{|c|}{ Reanalysis } \\
\hline 15 & MERRA (NASA) & $1 / 2^{\circ} \times 2 / 3^{\circ}$, global & $0-5 \mathrm{~cm}$ & Daily, 1979-2013 & Rienecker et al. (2011) \\
\hline 16 & MERRA-Land (NASA) & $1 / 2^{\circ} \times 2 / 3^{\circ}$, global & $0-5 \mathrm{~cm}$ & Daily, 1981-2013 & Reichle et al. (2011) \\
\hline 17 & ERA-40 (ECMWF) & $2.5^{\circ}$, global & Surface & 6-hourly, 1957-2002 & Uppala et al. (2005) \\
\hline 18 & ERA-Interim (ECMWF) & $0.75^{\circ}$, global & Surface & 6-hourly, 1979-2013 & Dee et al. (2011) \\
\hline 19 & ERA-Interim/Land (ECMWF) & $0.75^{\circ}$, global & Surface & 6-hourly, 1979-2010 & Balsamo et al. (2015) \\
\hline 20 & CFSR (NOAA) & $38 \mathrm{~km}$, global & $0-10 \mathrm{~cm}$ & 6-hourly, 1979-2006 & Saha et al. (2010) \\
\hline 21 & NARR (NOAA) & $32 \mathrm{~km}$, global & $0-10 \mathrm{~cm}$ & Monthly, 1979-2012 & Mesinger et al. (2006) \\
\hline \multicolumn{6}{|c|}{ Offline land data assimilations } \\
\hline 22 & GLDAS-Noah (NASA-NOAA) & $0.25^{\circ}$, global & $0-1 \mathrm{~cm}$ & Monthly, 2001-12 & Rodell et al. (2004) \\
\hline 23 & NLDAS-Noah (NOAA) & $0.125^{\circ}$, CONUS & $0-1 \mathrm{~cm}$ & Monthly, 1979-2012 & Cosgrove et al. (2003) \\
\hline
\end{tabular}

soil moisture at their corresponding probe from 2002 to 2011 (Stillman et al. 2014). The daily soil moisture at all 88 gauge locations are averaged together to create SM. While SM is highly correlated with observations, it cannot be considered ground truth. All soil moisture products analyzed here are listed in Table 2.

It should be noted that there are several caveats associated with directly comparing soil moisture products. First, the units are not always consistent. All products (except 3) in this study have units that are either volumetric $\left(\mathrm{m}^{3} \mathrm{~m}^{-3}\right)$ or can easily be converted (from $\mathrm{kg} \mathrm{m}^{-3}$ ) to volumetric. AMSR-E LPRM (3), TRMM LPRM (4), and MERRA (15) provide soil wetness (or fraction of saturation) that is multiplied by $0.35 \mathrm{~m}^{3} \mathrm{~m}^{-3}$ [i.e., the saturated soil moisture value used by Stillman et al. (2014)] for comparison with SM. Second, the measurement depth is variable (Table 2). The satellite products used here have overpass frequencies of once every 0.5-3 days. AMSR-E (2) has ascending [1330 local time (LT) at time of equator overpass] and descending (0130 LT) passes on most days, and the average of the two overpasses is used here.

The first five satellite soil moisture products (1-5) are derived from passive microwave instrument data and are chosen because they are commonly used in recent literature. Aquarius estimates surface soil moisture using horizontally polarized L-band brightness temperature at $1.41 \mathrm{GHz}$, AMSR-E (2) uses dual-polarized X-band frequency at $10.7 \mathrm{GHz}$, and AMSR-E LPRM (3) and TRMM LPRM (4) both estimate soil moisture from $\mathrm{X}$-band brightness temperature in conjunction with a land parameter retrieval model developed by NASA and VUA. AMSR-E LPRM is also available for C-band-based soil moisture retrievals; however, Owe et al. (2008) and de Jeu et al. (2008) showed that RFI degrades the performance at this frequency over the western United States. Therefore, only the X-band retrieval is shown here. SMOS (5) uses dual-polarized L-band frequency at $1.41 \mathrm{GHz}$. ASCAT (6) soil moisture is based on scatterometer measurements from C-band radar.

Soil moisture products (7-14) include many of the models used in CMIP5. Products 7-14 are from the first member in its ensemble (r1i1p1).

The reanalyses (15-21) and LDAS (22-23) are the most recent products available. ERA-Interim/Land (19) and MERRA-Land (16) have surface quantities adjusted offline by GPCP precipitation and NARR (21) assimilates gauge precipitation from multiple sources. 
They are included here in the reanalysis category, even though they can also be included in the LDAS category because they only adjust precipitation whereas the other LDAS products rely more heavily on several surface observations.

Note that even though large numbers of precipitation and soil moisture products are included in this study, they are far from complete. For example, there are many more CMIP5 models than the eight presented here. Multiple products are also available using data from the same satellite sensors; however, only one product for each sensor is shown. Additionally, other remotely sensed soil moisture products such as AMSR-2 (Parinussa et al. 2015) and gridded precipitation products such as GPCC (Becker et al. 2013) are available but were not included.

\section{c. Evaluation metrics}

Throughout this analysis, five statistical metrics are used to compare the products with in situ measurements over WGEW: correlation $R$, RMSD, mean bias (bias), bias-corrected RMSD (NRMSD), and a normalized standard deviation $\sigma_{N}$ :

$$
\begin{aligned}
R^{t} & =\frac{1}{n-1} \sum_{i=1}^{n}\left(\frac{X_{t, i}-\bar{X}_{t}}{\sigma_{t, x}}\right)\left(\frac{Y_{t, i}-\bar{Y}_{t}}{\sigma_{t, y}}\right), \\
\operatorname{RMSD}^{t} & =\left[\frac{1}{n} \sum_{i=1}^{n}\left(X_{t, i}-Y_{t, i}\right)^{2}\right]^{1 / 2}, \\
\operatorname{bias}^{t} & =\bar{Y}_{t}-\bar{X}_{t}, \\
\mathrm{NRMSD}^{t} & =\left\{\frac{1}{n} \sum_{i=1}^{n}\left[\left(X_{t, i}-\bar{X}_{t}\right)-\left(Y_{t, i}-\bar{Y}_{t}\right)\right]^{2}\right\}^{1 / 2}, \\
\sigma_{N}^{t} & =\frac{\sigma_{t, y}}{\sigma_{t, x}}
\end{aligned}
$$

where $X$ is the in situ data (Pobs or SM); $Y$ is the data from other products; $t$ is the time frame (whole data period: seasonal or daily; single year: daily); $n$ is the number of overlapping $X$ and $Y$ data points; $\sigma_{t, x}$ and $\sigma_{t, y}$ are the standard deviations of $X$ and $Y$ over $t$, respectively; and overbars represent the mean over $t$. Seasonal statistics are computed from seasonal averages whereas daily statistics are computed from all days of each season for the whole period when the product overlaps with in situ data (or for each year individually when specified). For example, a product's daily $R$ for June-August (JJA) precipitation refers to its correlation of daily precipitation in those months with that of Pobs for all years between 1956 and 2013 when the product is available (number of points $=$ number of years $\times 92$ ), whereas seasonal $R$ for JJA precipitation refers to correlation of JJA total precipitation for all years (number of points $=$ number of years). Daily $R$ for JJA can also refer to all days in a single JJA season when interannual variability is being evaluated (number of points $=92$ ) when specified.

The variable $R$ is a unitless test of how linear each product's relationship with in situ data is and ranges from -1 to 1 , with 1 being perfectly linearly correlated, -1 being perfectly linearly anticorrelated, and 0 having no correlation. RMSD describes how close the actual values are to in situ measurements, ranging from 0 to $\infty$ in the same unit as the in situ data, with 0 being a perfect fit. Bias implies the difference in the mean between each product and in situ measurements. NRMSD also ranges from 0 to $\infty$ in the same unit as the in situ data, where 0 represents a perfect fit after the bias is removed. The variable $\sigma_{N}$ describes the magnitude of the temporal variability compared with in situ values and ranges from 0 to $\infty$, where 1 means the in situ data and the product have equal temporal standard deviations and $<1(>1)$ means the product has a lower (higher) magnitude of temporal variability compared with in situ data. While models by nature do not reproduce individual storms, an ideal model would reproduce the observed magnitude and frequency of precipitation events. Therefore, $\sigma_{N}$ is a good statistic for evaluating models, particularly on the daily time scale, in place of RMSD and NRMSD. While only $\sigma_{N}$ and bias are directly relevant and meaningful in evaluating CMIP5 daily precipitation and soil moisture, all metrics are still shown for model results, as they provide a baseline for other data products to outperform.

\section{Precipitation product evaluations}

The annual cycle of precipitation in southeastern Arizona is characterized by a maximum in July and a secondary broader peak with its maximum in December and little to no springtime precipitation (Fig. 1). During the July-September period, encompassing most of the North American monsoon in this area, Pobs receives $170 \mathrm{~mm}$ of rain on average, or $62 \%$ of the annual total. All nonmodel products have mean annual cycles that show the timing of the peaks correctly.

GFDL CM3 (11) does a better job of reproducing the timing of the monsoon peak in July-August than the other models (Fig. 1c). Other model products [except HadGEM2-ES (10)] produce monsoon-like summer precipitation, but they do not show their peak precipitation in July-August. Four versions of the NCAR model (13-16) show a monsoon beginning in July but peaking in August-September, and MIROC5 (12) 

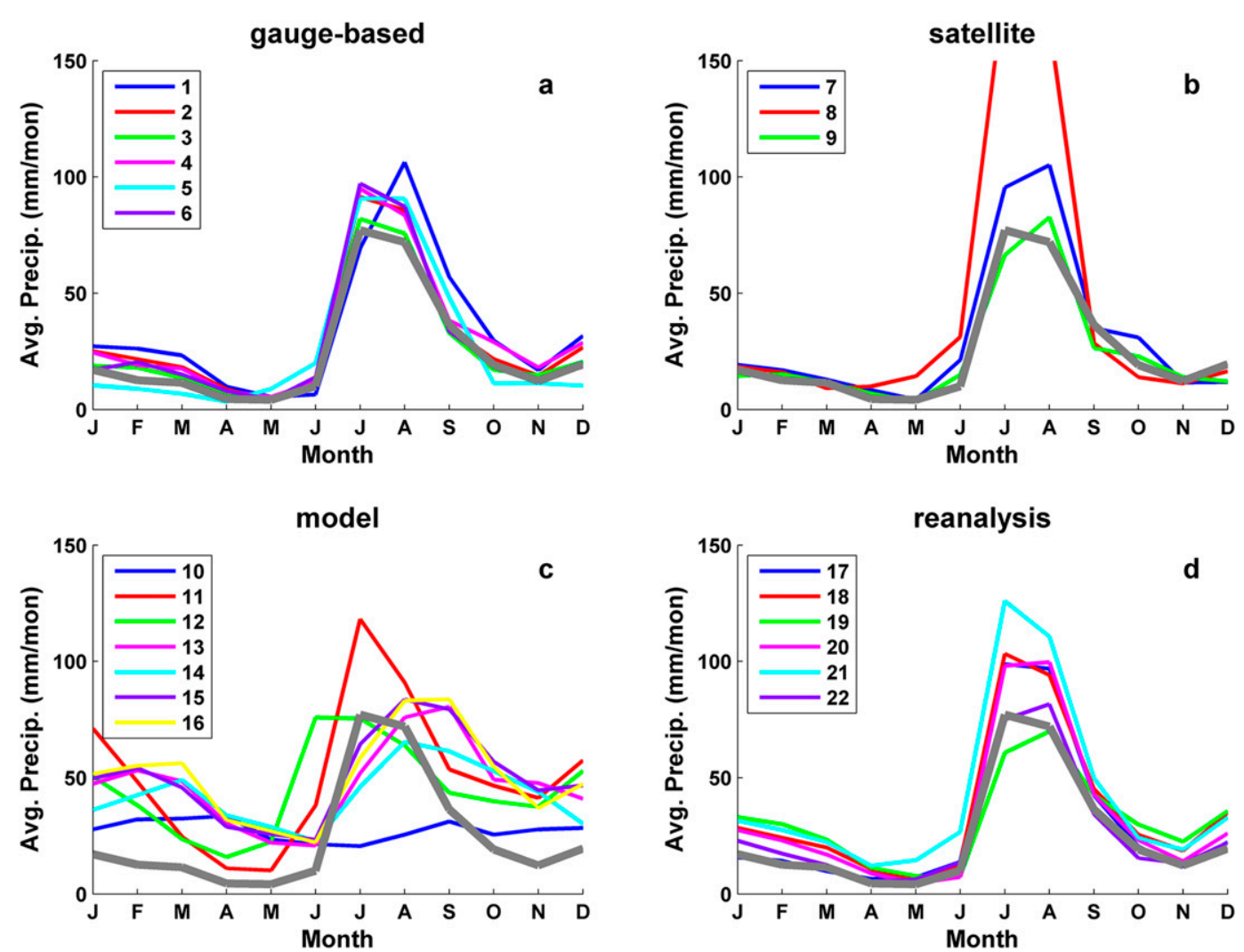

FIG. 1. Average monthly precipitation total for all (a) gauge-based, (b) satellite, (c) model, and (d) reanalysis products with WGEW monthly precipitation overlaid in gray.

shows an early monsoon start with the maximum in June. Offsets in the monsoon season may be due to a horizontal shift in the modeled general circulation patterns (Geil et al. 2013). Pobs in the May-October (warm period) half of the year is nearly 3 times its NovemberApril (cold period) precipitation. Almost all of the gauge-based, satellite, and reanalysis products show a similar ratio in the range of $2-4$. Stage IV (5) and PERSIANN (8) overestimate this ratio, and various model products estimate nearly equal distribution of precipitation in the warm and cold periods $(0.8-1.5)$.

Figure 2 shows the statistics [Eqs. (1), (3)-(5)] for seasonal and annual precipitation for all available years (Table 1), and the results are very similar using a common period (see Fig. S2 in the supplemental material). On average, Pobs is $16.39 \mathrm{~mm} \mathrm{month}^{-1}$ for DecemberFebruary (DJF), $53.03 \mathrm{~mm} \mathrm{month}^{-1}$ for JJA, and $24.68 \mathrm{~mm} \mathrm{month}^{-1}$ annually, with standard deviations of $11.32 \mathrm{~mm} \mathrm{month}^{-1}$ in DJF, $14.84 \mathrm{~mm} \mathrm{month}^{-1}$ in JJA, and $5.86 \mathrm{~mm} \mathrm{month}^{-1}$ annually. Gridded gauge or merged precipitation products are often used for evaluation of other products; however, some of the gauge-based products do not do as well as reanalyses products in some performance metrics.
Most products perform better in the winter than in the summer, with lower NRMSDs (Fig. 2c) and higher $R$ values (Fig. 2a). With the exception of the models, all precipitation products are significantly correlated with Pobs with median values of $0.83,0.46$, and 0.68 for the gauge-based, satellite, and reanalysis annual precipitation, respectively (Fig. 2a). In general, the satellite products perform similarly to the reanalyses except for the poor correlation of PERSIANN (8) annual precipitation. The poorer performance of the models with respect to the other products on seasonal time scales is partly due to the shift of the monsoon onset and the inflated secondary wintertime precipitation peak (Fig. 1). Throughout the monsoon region within the United States, between $5 \%$ and $20 \%$ of the total summer precipitation comes from tropical cyclone remnants (Corbosiero et al. 2009). Because models do not represent tropical cyclone frequency well (Sheffield et al. 2013), tropical cyclone activity may have a significant impact on model performance during the summer months.

All products have wet annual biases compared with Pobs (Fig. 2b). For instance, PERSIANN (8) estimates over twice as much July-September precipitation 

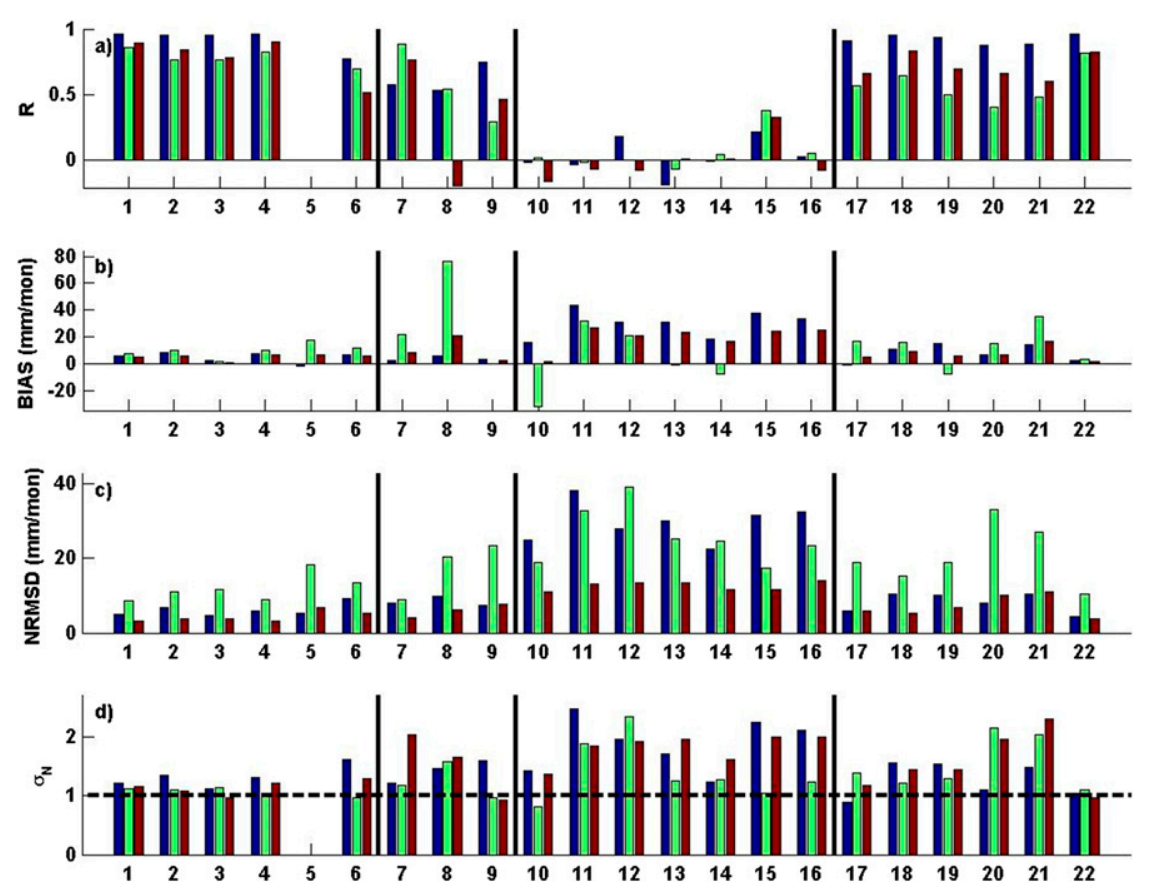

FIG. 2. Performance statistics (a) $R$, (b) bias, (c) NRMSD, and (d) $\sigma_{N}$ as represented by the four metrics in Eqs. (1), (3), (4), and (5), of each monthly precipitation product for DJF (blue), JJA (green), and annual mean (red). Variables $R$ and $\sigma_{N}$ are not shown for products with less than 10 years of complete data [such as stage IV (5)]

(130.14 $\left.\mathrm{mm} \mathrm{month}^{-1}\right)$ as Pobs $\left(53.03 \mathrm{~mm} \mathrm{month}^{-1}\right)$. The PERSIANN (8) developers desire to have a satelliteonly product rather than a gauge-satellite merged product. This may be one reason for its poor performance compared with other gauge-satellite merged products. The median annual mean biases of gaugebased, satellite, model, and reanalysis products are 6.07, $8.58,23.11$, and $6.46 \mathrm{~mm} \mathrm{month}^{-1}$, respectively. These small biases in the nonmodel products could be partly accounted for by the scale mismatch, which is discussed in section 5.

Many products slightly overestimate the magnitude of interannual variability of annual precipitation compared with Pobs (Fig. 2d). While the gauge-based products all have $\sigma_{N}$ values close to 1 , the median value for models is nearly 2 , and for the satellite and reanalysis products the median values are approximately 1.5 .

Of all products, CPC (1) and PRISM (4) perform best on interannual time scales, with the highest correlation (Fig. 2a) and lowest NRMSD (Fig. 2c). PREC/L (2), University of Delaware (3), and NARR (22) perform nearly as well. Out of the reanalyses, MERRA-Land (18) and NARR (22) perform best, where MERRALand (18) has the best correlation and NARR (22) outperforms the rest in bias and interannual variability magnitude. TRMM (7) is the best-performing satellite product. The only model with annual precipitation that is significantly correlated with Pobs is CESM, version 1 (with FASTCHEM) (15), with $R=0.33$.

Figure 3 shows the same performance statistics for daily precipitation. For consistency, all metrics are shown for the CMIP5 models. However, as mentioned previously, these models produce synthetic realizations of climate variability, and hence their daily precipitation products are expected to have low $R$ and high NRMSD. All of the nonmodel products are significantly correlated with Pobs even on daily time scales (Fig. 3a), with annual median values of $0.54,0.39$, and 0.49 for gaugebased, satellite, and reanalysis products, respectively. MERRA-Land (18) has the highest correlation (Fig. 3a) of any product on daily time scales, closely followed by CPC (1) and NARR (22), while NARR (22) has the lowest NRMSD (Fig. 3c). The NRMSDs of even the nonmodel products are actually between 3 and 5 times the average daily Pobs of $0.81 \mathrm{~mm} \mathrm{day}^{-1}$. Compared with the daily standard deviations in Pobs of $\sigma^{\mathrm{DJF}}=2.35$, $\sigma^{\mathrm{JJA}}=4.14$, and $\sigma^{\text {annual }}=2.95 \mathrm{~mm} \mathrm{day}^{-1}$, all of the models overestimate daily $\sigma^{\mathrm{DJF}}$ and most underestimate $\sigma^{\mathrm{JJA}}$, leading to $\sigma_{N}^{\text {annual }}$ generally fairly close to 1 (Fig. 3d). Overall, the gauges perform best, models perform the worst, and satellite and reanalysis products perform comparably. Results are also very similar using a common period (see Fig. S1 in the supplemental material). 

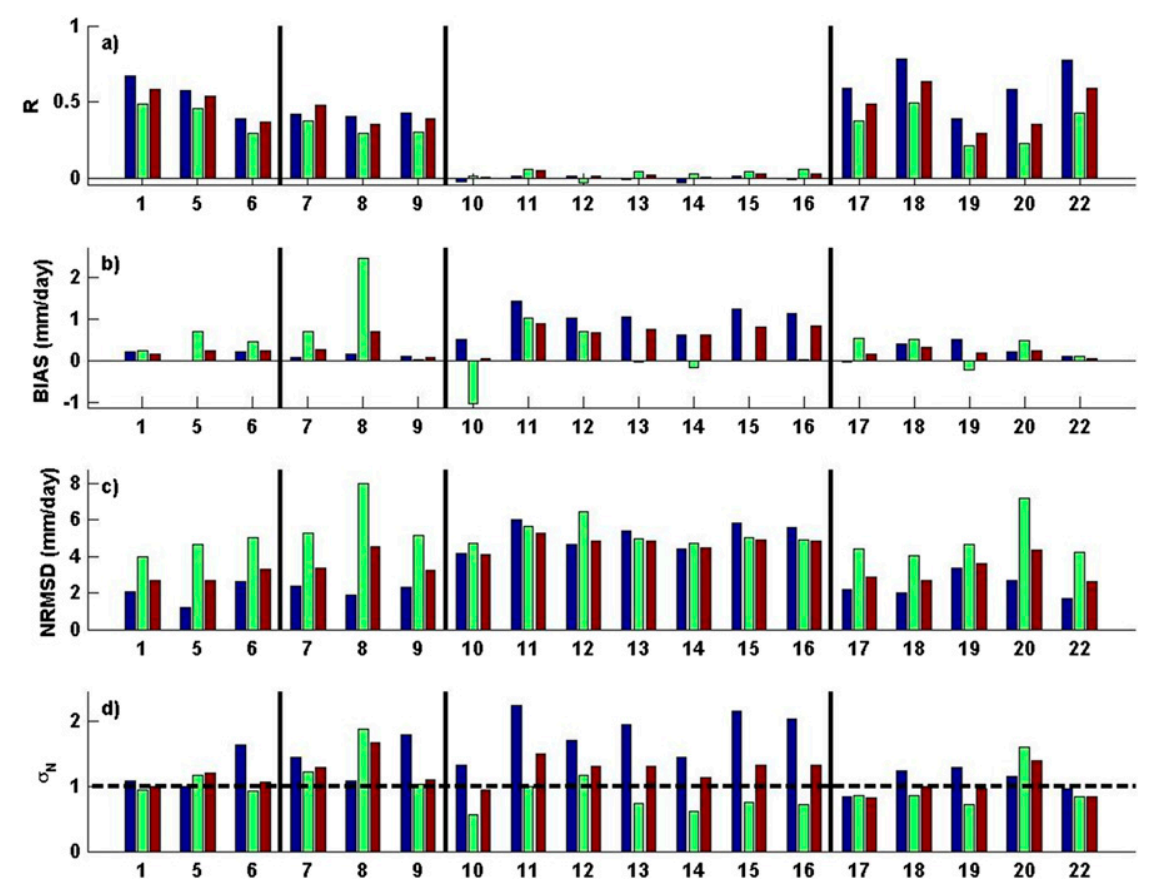

FIG. 3. Performance statistics (a) $R$, (b) bias, (c) NRMSD, and (d) $\sigma_{N}$ of each daily precipitation product for DJF (blue), JJA (green), and annual mean (red).

From year to year, there is a high degree of variability in the daily $R$ values from nonmodel products (Fig. 4). All of these nonmodel products have significant daily correlation $(p<0.01)$ with Pobs in all years. The models' daily precipitation is not significantly correlated with Pobs in any year (results not shown). One interesting feature is that the quality of CPC (1) compared with Pobs degrades steadily over the time period with decreasing $R$ (Fig. 4) and increasing RMSD (not shown). Over the period from 1956 to 2006 CPC's $R$ values range from $\sim 0.2$ to 0.9 and have a significant trend $(p<0.01)$ of -0.093 decade $^{-1}$. CPC's RMSD also has a significant trend $(p<0.01)$ of $0.36 \mathrm{~mm} \mathrm{day}^{-1}$ decade $^{-1}$ (not shown). Additionally, while MERRA-Land (18) generally performs very well, during 1996-98 (particularly in summer) it has a much lower correlation with Pobs than the rest of the years. Further studies are needed to explore the reason for this abnormal and poor correlation in the summer of 1996-98. MERRA-Land (18) also shows a significant trend in RMSD of $-0.22 \mathrm{~mm} \mathrm{day}^{-1}$ decade $^{-1}$ from 1981 to 2013. The performance of the products in Fig. 4 does not seem to be a function of the annual total rain, average intensity (total rain divided by number of days with rain), or frequency (number of days with rain divided by total number of days; not shown).

Following J. Liu et al. (2012), Fig. 5 displays precipitation intensity of all of the products in five ranges: negligible $\left(<0.1 \mathrm{~mm} \mathrm{day}^{-1}\right)$, drizzle $\left(0.1-3 \mathrm{~mm} \mathrm{day}^{-1}\right)$, light (3-10 mm day $\left.{ }^{-1}\right)$, medium $\left(10-25 \mathrm{~mm} \mathrm{day}^{-1}\right)$, and heavy $\left(>25 \mathrm{~mm} \mathrm{day}^{-1}\right)$. WGEW is located in a semiarid region, where on most days $(80 \%)$ there is no rain (Fig. 5a). All nonmodel products capture well the frequency distribution of the total number of days when precipitation falls in each intensity category (Fig. 5). In
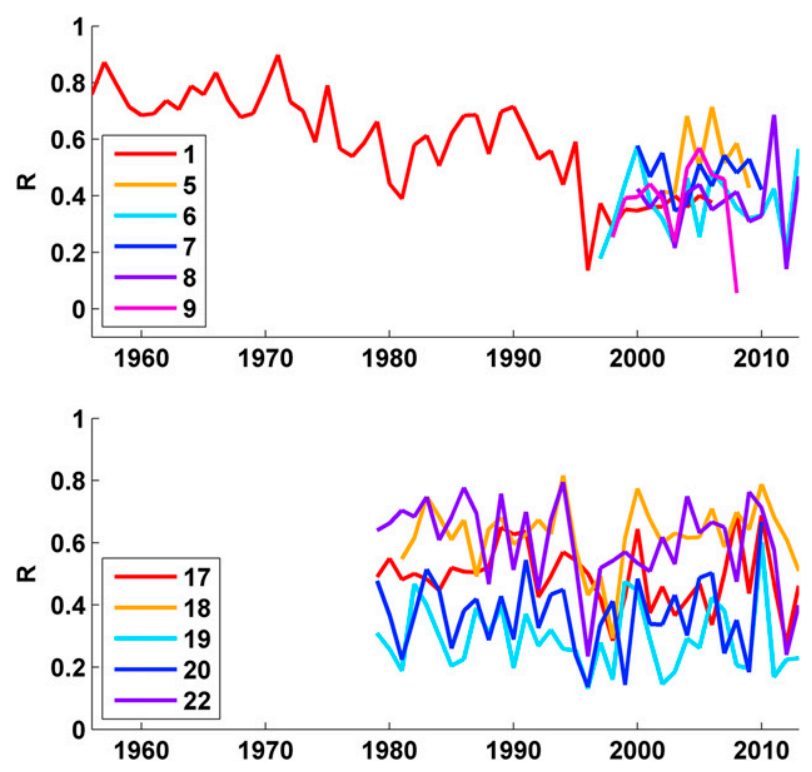

FIG. 4. Values of $R$ for each nonmodel product's daily precipitation for each year vs WGEW: (top) gauge-based and satellite products and (bottom) reanalysis products. 

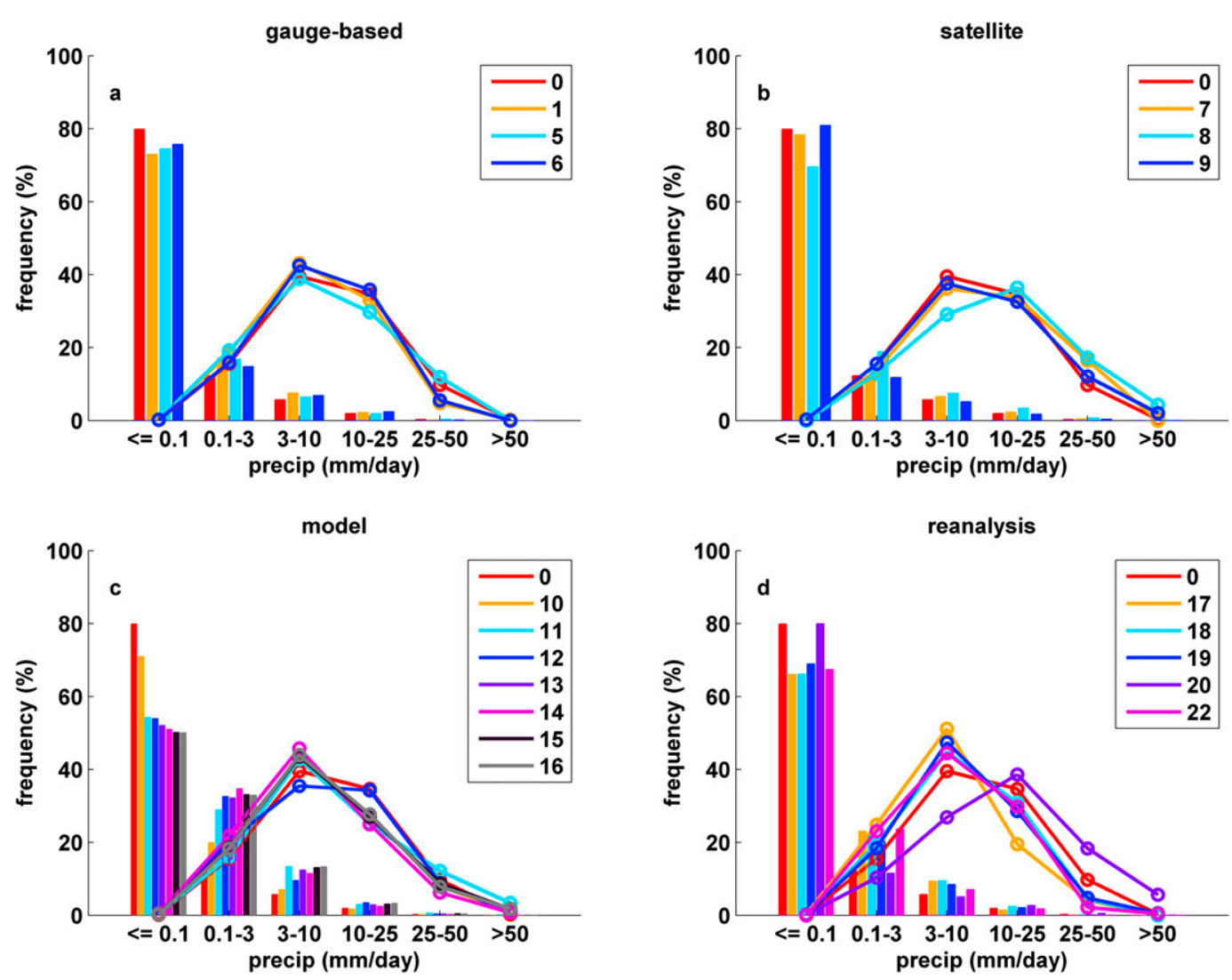

FIG. 5. For (a) gauge-based, (b) satellite, (c) model, and (d) reanalysis products, the percentage of the total number of days when precipitation fell into each intensity category (bars) and percentage of annual total precipitation that fell into each intensity category (lines). WGEW is overlaid in each box as the red bar and red line.

contrast, most model products underestimate the frequency in the negligible precipitation category and overestimate the occurrence of drizzle and light precipitation, consistent with the findings of Chen et al. (1996).

Over $70 \%$ of the total Pobs amount falls as light to medium precipitation (Fig. 5). It should be noted that while summertime thunderstorms have high hourly rain rates, they are also short lived, so the daily intensity remains relatively low. Most products estimate approximately the same occurrence of light to medium intensities. Interestingly, all of the models except MIROC5 (12) represent intensity contribution better than some of the satellite-based and reanalysis products (Figs. 5b-d).

Pobs never experiences intensities greater than $50 \mathrm{~mm}_{\text {day }^{-1}}$; however, over $4 \%$ of the total precipitation in PERSIANN (8) and CFSR (20) falls in that intensity range. Figure 5 only shows the overall intensity distribution for the whole year. When the data are separated into summer and winter, the satellite products [except PERSIANN (8)] are found to better estimate the contribution intensities in the summer than in the winter, while all models [except HadGEM2-ES (10)] overestimate medium to heavy precipitation in the winter (results not shown).

The precipitation trends from all products have also been evaluated against Pobs. It should be noted that a trend is questionable if the number of measurements changes over time (e.g., assimilating new observation) in a product. First, trends are assessed for the common period of 1958-2002 for the 13 products with data spanning this time frame. Most products do not show any significant trends for seasonal or annual mean precipitation for this period, in agreement with Pobs. However, HadGEM2-ES (10) shows a trend of $-20.55 \mathrm{~mm} \mathrm{decade}^{-1}(p<0.01)$ for its DJF precipitation and JRA-55 (21) shows an increase of $64.13 \mathrm{~mm} \mathrm{decade}^{-1}(p<0.01)$ for annual precipitation and increasing JJA precipitation of $34.78 \mathrm{~mm} \mathrm{decade}^{-1}$ $(p<0.01)$. JRA-55's (21) large increasing trend is mostly manifested in a sharp increase of annual precipitation amount from $<300 \mathrm{~mm}$ in 1975 to $>900 \mathrm{~mm}$ in 1983. This finding of the spurious jump is expected to help the JRA-55 (21) developers to pinpoint the reasons. 

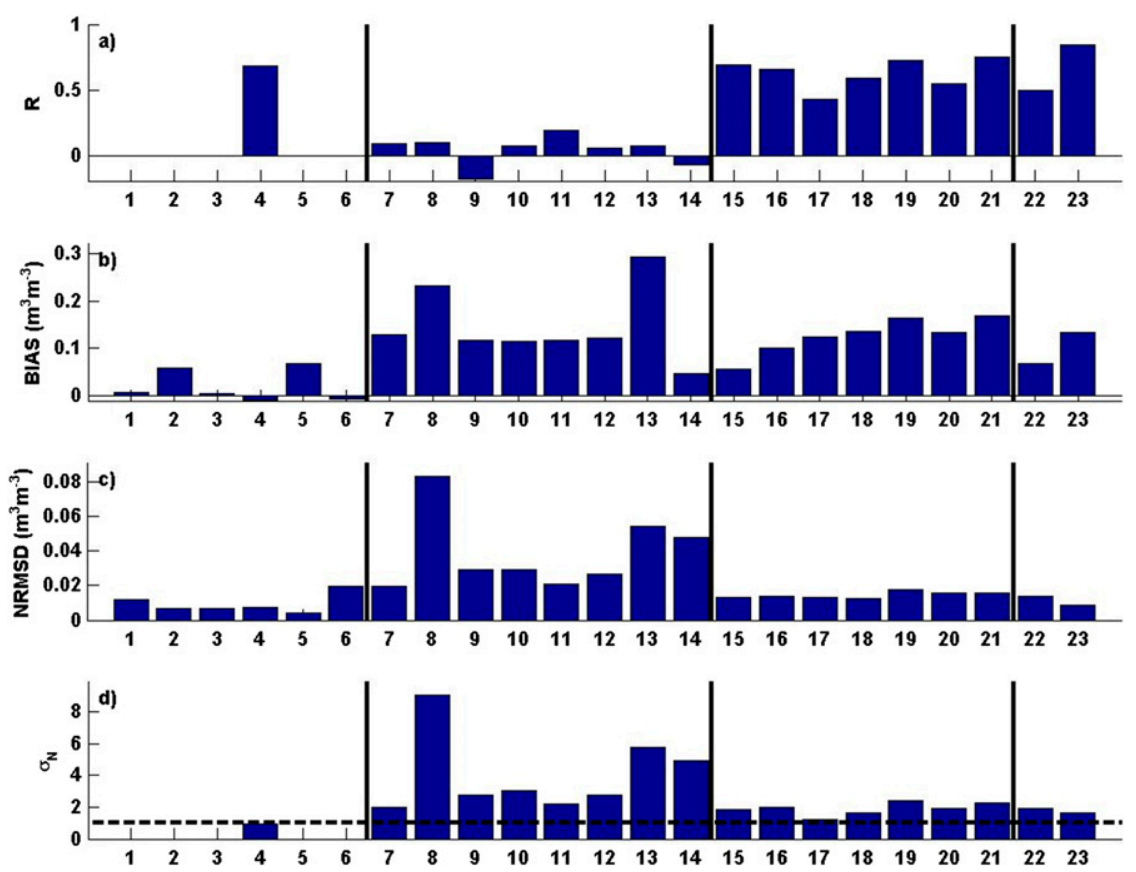

FIG. 6. Performance statistics (a) $R$, (b) bias, (c) NRMSD, and (d) $\sigma_{N}$ of each monthly summer (July-September) soil moisture product against SM. Variables $R$ and $\sigma_{N}$ are shown only for products with at least 10 years of data.

For each product, a trend analysis has also been done for its entire overlapping period with Pobs. Out of the 17 products with at least 20 years of data, only ERAInterim (19) and JRA-55 (21) have trends over their entire periods overlapping Pobs while Pobs does not have any trends. This trend in ERA-Interim (19) is consistent with the finding of Bosilovich (2013) (i.e., ERA-Interim has decreasing trends over most regions of the United States that were not observed). For the common period of MERRA-Land (18) and Pobs (19812013), Pobs has a significant trend (annual; $-4.84 \mathrm{~mm} \mathrm{yr}^{-1}$ ). MERRA-Land also shows a decreasing $\left(-5.69 \mathrm{~mm} \mathrm{yr}^{-1}\right)$ trend over this period.

\section{Soil moisture evaluations}

Figure 6 compares all summer (July-September) soil moisture products against SM. Overall models perform worst for all four metrics among the different categories, while satellite data perform best for two metrics (bias and NRMSD). Of the satellite products, only TRMM LPRM (4) has a long enough data record (at least 10 years of data) for computing $R$ or $\sigma_{N}$. NLDAS-Noah (23) performs best with $R$ for all summer months of 0.84 and NRMSD of $0.0090 \mathrm{~m}^{3} \mathrm{~m}^{-3}$ compared with SM. However, it has a bias of $+0.13 \mathrm{~m}^{3} \mathrm{~m}^{-3}$, which is very large compared with the summer average in WGEW of $0.067 \mathrm{~m}^{3} \mathrm{~m}^{-3}$ from SM. In fact, all products are positively biased (wetter than observed) except for TRMM LPRM (4) and ASCAT (6), with the smallest absolute bias associated with AMSR-E LPRM (3). The satellite products have the lowest mean biases, with a median value of $0.0056 \mathrm{~m}^{3} \mathrm{~m}^{-3}$, whereas the models, reanalyses, and LDAS have biases that are greater than $0.10 \mathrm{~m}^{3} \mathrm{~m}^{-3}$. HadCM3 (13) has the largest bias of $0.29 \mathrm{~m}^{3} \mathrm{~m}^{-3}$, which is nearly fully saturated, and is not realistic for this semiarid climate.

None of the models produce summer soil moisture that is significantly correlated with SM (Fig. 6a). The reanalyses and LDAS have similar median correlations with SM of 0.66 and 0.67 , respectively. Satellite, reanalysis, and LDAS soil moisture products have relatively low NRMSDs with median values of $0.0070,0.014$, and $0.011 \mathrm{~m}^{3} \mathrm{~m}^{-3}$, respectively. Models have larger NRMSDs ranging from $\sim 0.02$ to $0.08 \mathrm{~m}^{3} \mathrm{~m}^{-3}$, with a median value of $0.029 \mathrm{~m}^{3} \mathrm{~m}^{-3}$.

Most products have almost twice the interannual summer [July-September (JAS)] soil moisture standard deviation as SM $\left(\sigma^{\mathrm{JAS}}=0.0093 \mathrm{~m}^{3} \mathrm{~m}^{-3}\right.$; Fig. $\left.6 \mathrm{~d}\right)$. In particular, MIROC5 (8) estimates 9 times the standard deviation of summer soil moisture as that of SM. MERRA (15) performs best out of the reanalysis products, with the lowest mean bias and better than average $R$ values and NRMSDs. NLDAS-Noah (23) has better $R$ and NRMSD than GLDAS-Noah (22), but has a larger bias. 

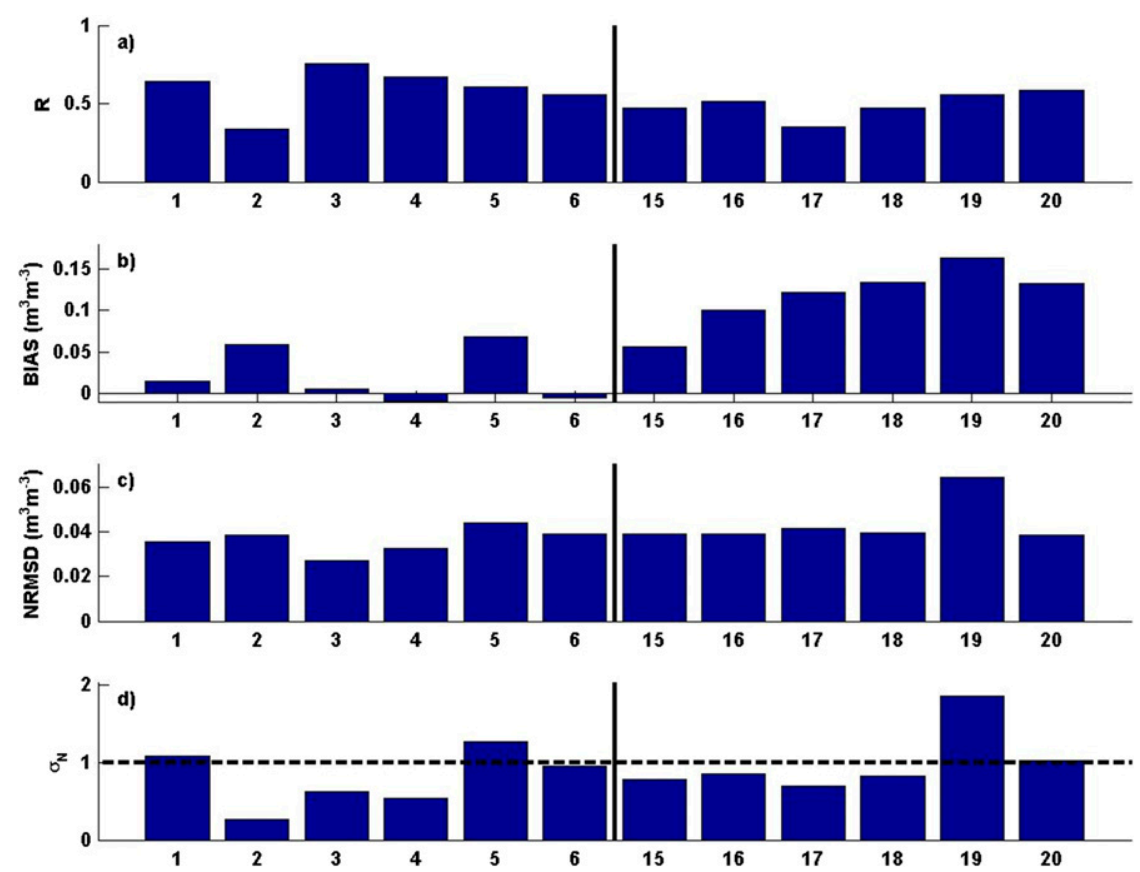

FIG. 7. Performance statistics (a) $R$, (b) bias, (c) NRMSD, and (d) $\sigma_{N}$ of each daily summer soil moisture product.

Day-to-day soil moisture variability is evaluated in Fig. 7. As a reference point, during a field campaign as part of the SMEX04, gravimetric samples were taken throughout WGEW on 11 days during the summer and the range of spatially averaged values was $\sim 0.05$ $0.17 \mathrm{~m}^{3} \mathrm{~m}^{-3}$ (Stillman et al. 2014). This is the approximate range of SM except for a few rainy days that push the spatially averaged soil moisture just over $0.2 \mathrm{~m}^{3} \mathrm{~m}^{-3}$. Compared with this range, the mean biases and NRMSDs in daily soil moisture are often quite large.

Satellite products outperform reanalyses with higher $R$ (median values of 0.62 and 0.49 , respectively) and lower mean biases (median values of 0.010 and $0.13 \mathrm{~m}^{3} \mathrm{~m}^{-3}$, respectively). Over the five summers with available data, AMSR-E LPRM (3) performs the best overall on daily time scales, followed by TRMM LPRM (4). The improvements between ERA-40 (17) and ERA-Interim (18) are noticeable in $R$ and $\sigma_{N}$; however, there is actually a slight increase in the bias. With the exceptions of satellite products 2-4 and ERA-Interim/ Land (19), the day-to-day soil moisture variability of each of the products is close to that of SM $\left(\sigma^{\mathrm{JAS}}=\right.$ $0.042 \mathrm{~m}^{3} \mathrm{~m}^{-3}$ for SM). As ERA-Interim/Land (19) incorporates GPCP precipitation, it correlates better with observations than ERA-Interim (18), but its NRMSD is higher.

Figure 8 shows $R$ of each product's daily soil moisture with SM. The spread in the $R$ values from year to year are large, particularly in ERA-40 (17), ERA-Interim
(18), and ERA-Interim/Land (19), which range from insignificantly negative to $\sim 0.8$. This variability does not seem to be related to average soil moisture, total precipitation, or average precipitation intensity (not shown). None of the $R$ time series show significant trends over their available range of years; however, several of the reanalysis products have a peak in their correlation around 2005 and a low in their correlation with SM in the late 1990s. Further research is needed to identify the reasons.

Figure 9 shows the relationship between each daily soil moisture product and SM. For each $0.01 \mathrm{~m}^{3} \mathrm{~m}^{-3}$ increment from 0 to $0.25 \mathrm{~m}^{3} \mathrm{~m}^{-3}$, the median value of each product for all days during which SM was within each $0.01 \mathrm{~m}^{3} \mathrm{~m}^{-3}$ bin is plotted on the $y$ axis versus its bin on the $x$ axis. All of the lines have positive slopes; however, some slopes are very shallow. For instance, AMSR-E (2) has a slope of 0.057. Several of the reanalysis products, as well as AMSR-E LPRM (3) and TRMM LPRM (4), are more sensitive to changes in soil moisture at lower SM values than at higher SM values. For instance, MERRA (15) and MERRA-Land (16) have the most dramatic increases in lower SM values. MERRA-Land (16) increases from 0.052 to $0.15 \mathrm{~m}^{3} \mathrm{~m}^{-3}$ when SM increases from 0.005 to just $0.025 \mathrm{~m}^{3} \mathrm{~m}^{-3}$, and then plateaus. Most of the satellite products (1-6) were measured for only a few years, each leading to the less smooth curves in Fig. 9. Note that the Aquarius (1) data were not available on days when the average soil 

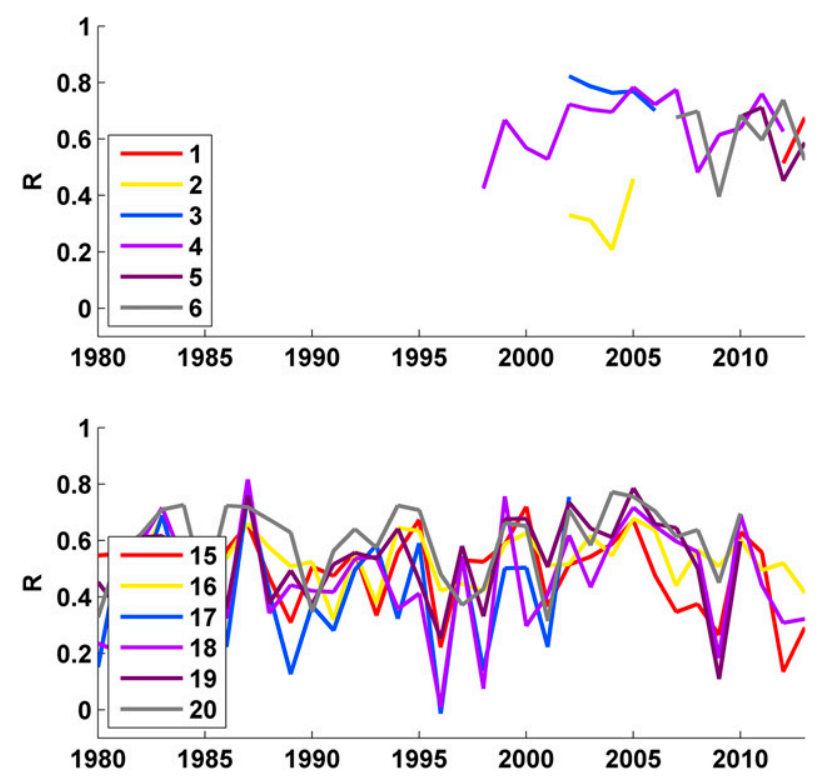

FIG. 8. Correlation of each product's daily summer soil moisture for each year vs SM for (top) satellite and (bottom) reanalysis products.

moisture from SM is greater than $0.15 \mathrm{~m}^{3} \mathrm{~m}^{-3}$. While ERA-Interim/Land (19) tends to be more sensitive at drier values and has a wet bias with an intercept of $0.15 \mathrm{~m}^{3} \mathrm{~m}^{-3}$, it has the closest to one-to-one ratio of all products, with a slope of 1.08 .

Following ERA-Interim/Land (19), SMOS (5) is the next closest to a one-to-one ratio with a slope of 0.67 ; however, it has a large wet bias with an intercept of $0.084 \mathrm{~m}^{3} \mathrm{~m}^{-3}$. The smallest wet bias is associated with ASCAT (6) with an intercept of $0.022 \mathrm{~m}^{3} \mathrm{~m}^{-3}$. Overall, Aquarius (1) and ASCAT (6) have the smallest wet biases and closest [besides SMOS (5)] one-to-one relationship with SM of the satellite products. L-band brightness temperature, which is used by Aquarius (1) and SMOS (5) to estimate soil moisture, has been shown to have a linear relationship with soil moisture (Schmugge and Jackson 1994). This is the reason for the excellent correlation of Aquarius (1) and SMOS (5) results with SM in Fig. 9. On the other hand, the retrieval algorithm of SMOS (5) needs to be revised to reduce its wet bias in Fig. 9. An updated version of SMOS soil moisture was released in May 2015, which may have a reduced bias.

For the 17 products with at least 20 years of data during 1956-2013, trends have also been analyzed for the period of overlap with SM. Fifteen products agree with the SM data with no significant trends, and only MIROC5 (8) and ERA-40 (17) show significant trends $(p<0.01)$ at $-6.50 \times 10^{-3} \mathrm{~m}^{3} \mathrm{~m}^{-3} \mathrm{decade}^{-1}$ from 1956 to 2012 and $3.66 \times 10^{-3} \mathrm{~m}^{3} \mathrm{~m}^{-3}$ decade $^{-1}$ from 1957 to 2002 , respectively.

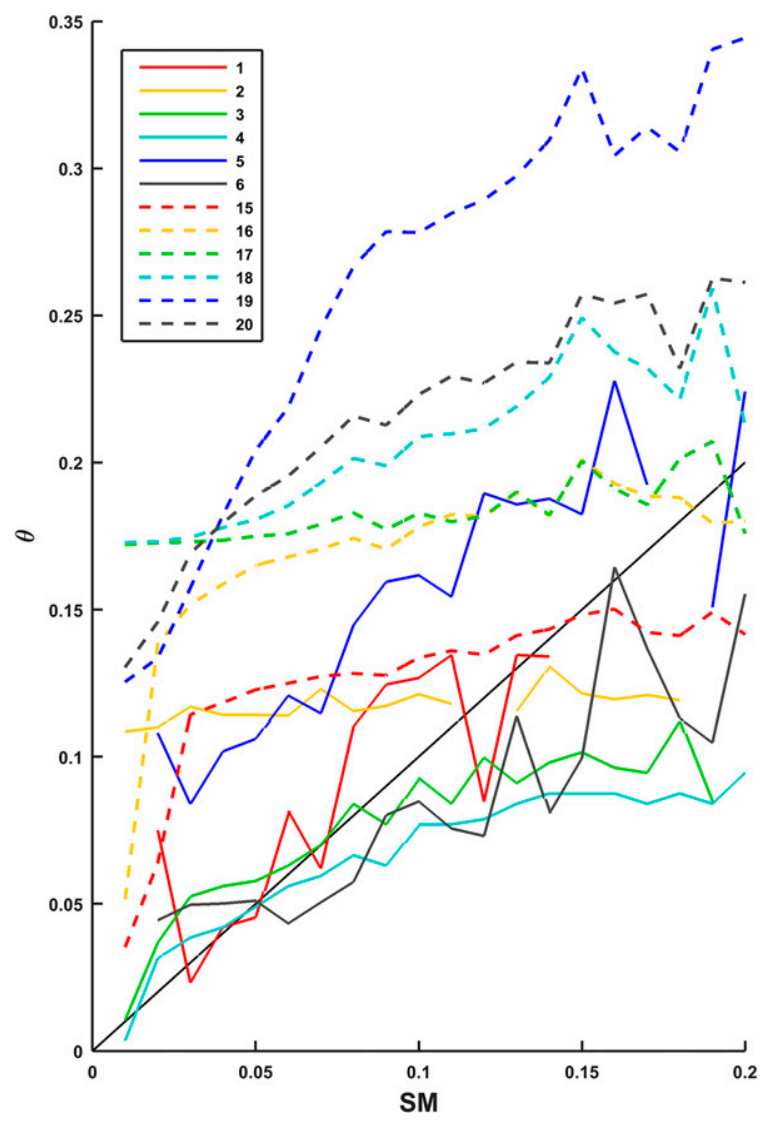

FIG. 9. Median daily summer soil moisture for each product for each incremental SM daily value.

\section{Uncertainties due to horizontal scale mismatch}

For each product whose spatial resolution is coarser than the area of WGEW, the grid cell closest to the center of WGEW $\left(31.71^{\circ} \mathrm{N}, 110.01^{\circ} \mathrm{W}\right)$ is used for evaluation. Because of the spatial variability of precipitation and soil moisture, there are inherent differences between watershed-scale values and coarser-resolution products. This scale difference in soil moisture has been addressed through a variety of upscaling techniques (Crow et al. 2012). While Pobs and SM upscale from point scale to the watershed scale (of $150 \mathrm{~km}^{2}$ ), an obvious question is, for the many products in Tables 1 and 2 that have coarser resolutions than Pobs (for precipitation) and SM (for soil moisture) over an area of $150 \mathrm{~km}^{2}$, how does the scale mismatch affect the comparison in our study?

Here we use the PRISM (4) precipitation data to address this issue for several reasons: 1) PRISM has a fine spatial resolution $(4 \mathrm{~km})$ and extensive areal coverage, 2) PRISM has the best correlation of all products for annual precipitation (0.90; Fig. 2), and 3) precipitation spatial heterogeneity is the primary driver of soil 

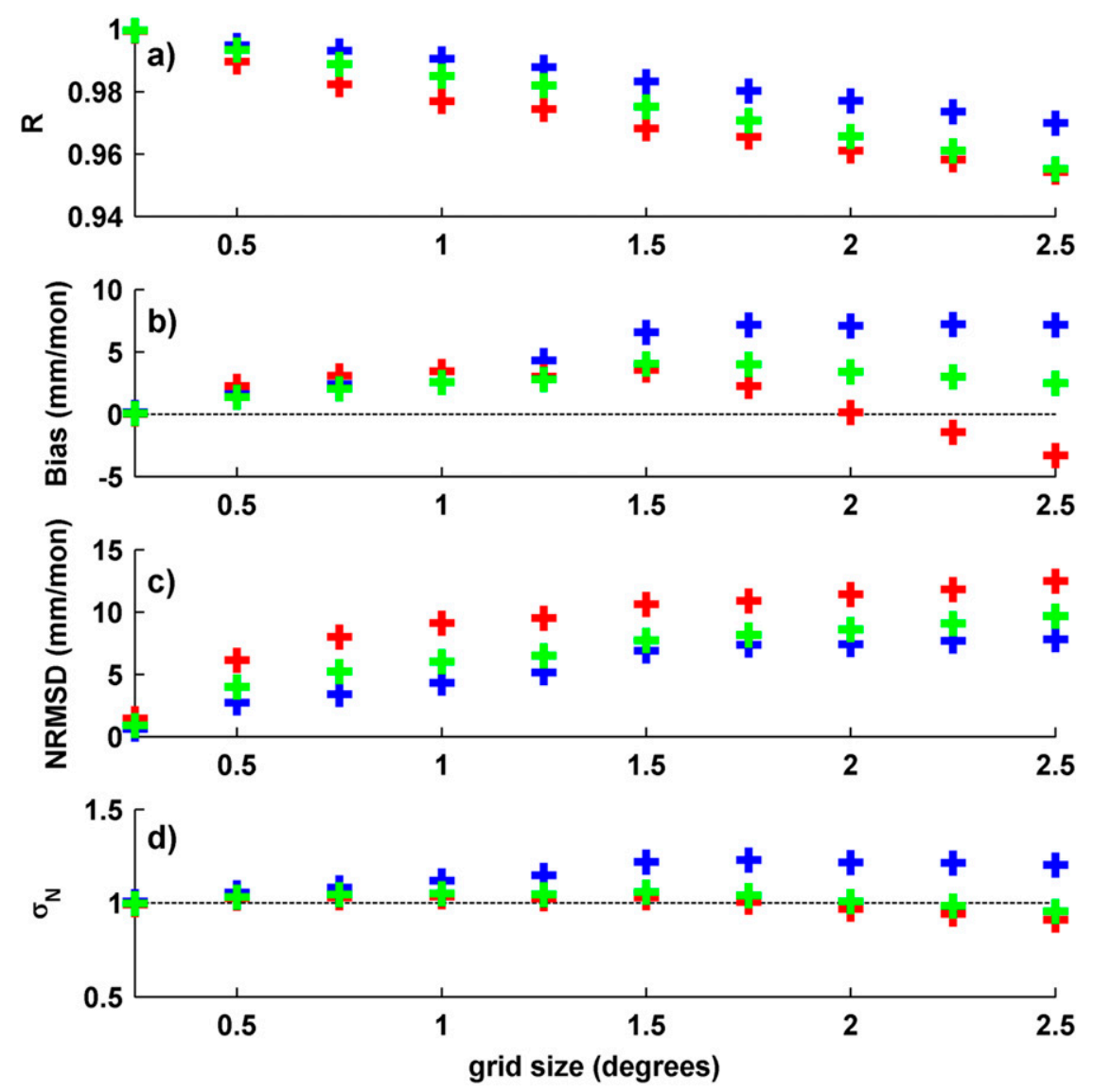

FIG. 10. Performance statistics (a) $R$, (b) bias, (c) NRMSD, and (d) $\sigma_{N}$ of average monthly PRISM precipitation over grid boxes with various grid sizes $\left({ }^{\circ} ; x\right.$ axis) centered at the center of WGEW compared with average monthly PRISM precipitation over WGEW for DJF (blue), JJA (red), and annual mean (green).

moisture variability. The average PRISM precipitation over the WGEW area, computed as the average of all PRISM 4-km grid cells whose centers lie within the perimeter of WGEW, is compared with the average PRISM precipitation over grid cells with various grid sizes centered at the center of WGEW $\left(31.71^{\circ} \mathrm{N}, 110.01^{\circ} \mathrm{W}\right)$.

These comparisons [where $X$ is PRISM over WGEW and $Y$ is PRISM over larger grid cells in Eqs. (1), (3)-(5)] are shown in Fig. 10. The correlation is very high, even at a grid size of $2.5^{\circ}$ for winter (DJF; 0.97) and for summer (JJA) and annual mean (0.95; Fig. 10a). The mean bias is within $5 \mathrm{~mm}$ month $^{-1}$ in magnitude for JJA and annual precipitation and within $8 \mathrm{~mm}$ month $^{-1}$ for DJF precipitation (Fig. 10b). NRMSD increases with grid size, but it is still within 8,12 , and $10 \mathrm{~mm} \mathrm{month}^{-1}$ for DJF, JJA, and annual precipitation, respectively (Fig. 10c). Summer and annual $\sigma_{N}$ are fairly constant and close to 1 across all resolutions, while winter $\sigma_{N}$ varies with grid sizes, reaching a peak of 1.23 at a grid size of $1.75^{\circ}$. Figure 10 demonstrates that the uncertainties due to the scale mismatch between the WGEW area of $150 \mathrm{~km}^{2}$ and coarser grid cells with grid sizes from $0.25^{\circ}$ to $2.5^{\circ}$ are relatively small, and they have very small impacts on the results presented in sections 2 and 3.

Because WGEW is close to the southern border of the United States and PRISM data only cover the continental United States, grid boxes with a grid size greater than $\sim 1^{\circ}$ contain missing data (over Mexico). To quantify the impact of excluding Mexico on the results in Fig. 10, $2.5^{\circ}$ monthly stage IV (5) precipitation data over the United States only $P_{u}$ (like in the analysis in Fig. 10) is compared with $2.5^{\circ}$ monthly stage IV (5) data over both the United States and Mexico $P_{m}$. Stage IV precipitation has 4-km resolution over the United States but also includes data over part of northern Mexico, so that data are available with $89 \%$ or more spatial coverage for the $2.5^{\circ}$ grid box over the WGEW. The results are very similar, with a bias of $-0.91 \mathrm{~mm}$ month $^{-1}$ (the United States alone is slightly drier than the United States and Mexico together) and an NRMSD of $0.65 \mathrm{~mm}$ month $^{-1}$. 

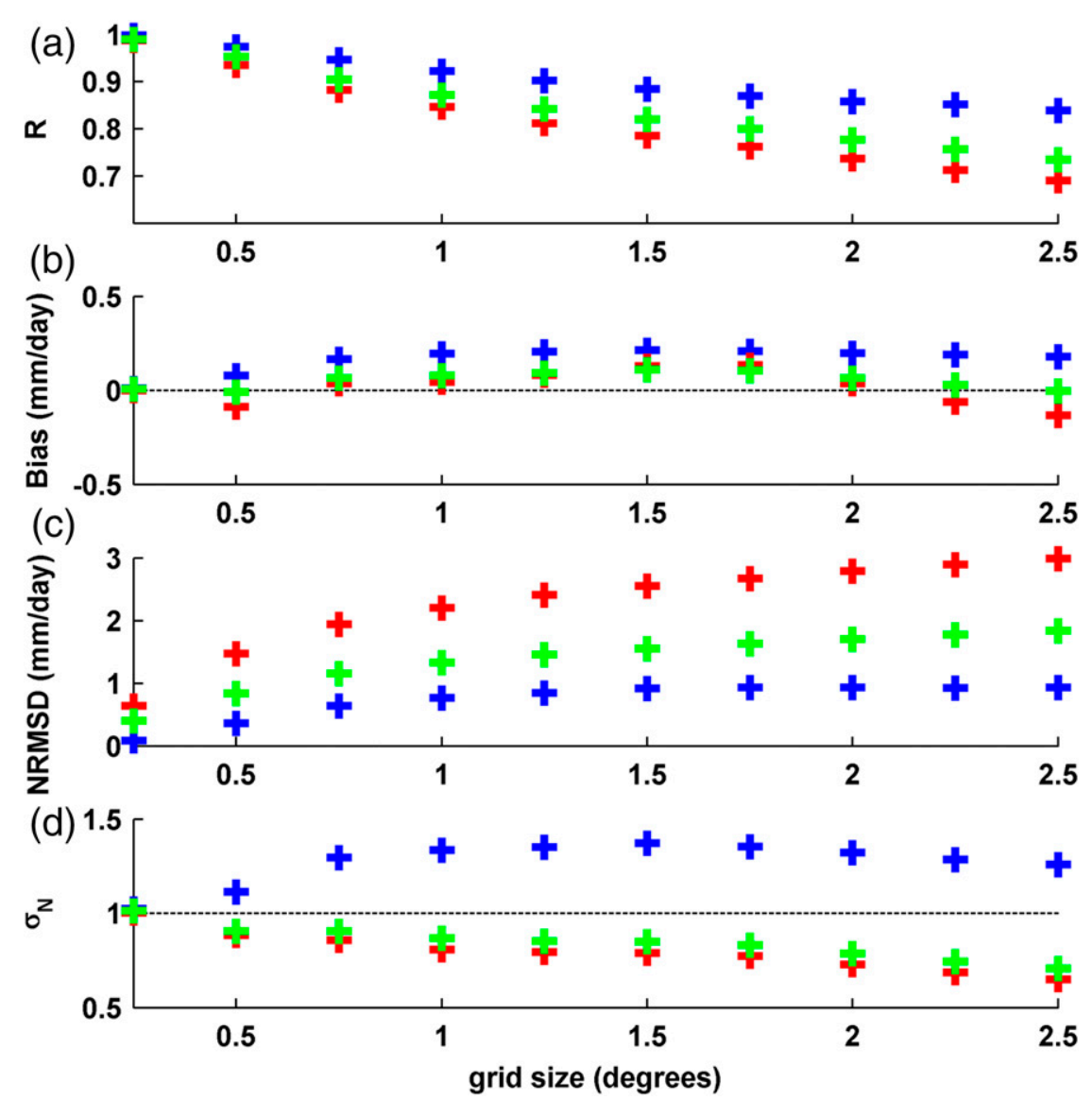

FIG. 11. Performance statistics (a) $R$, (b) bias, (c) NRMSD, and (d) $\sigma_{N}$ of average daily stage IV precipitation over grid boxes with various grid sizes $\left({ }^{\circ} ; x\right.$ axis) centered at the center of WGEW compared with average daily stage IV precipitation over WGEW for DJF (blue), JJA (red), and all year (green).

Compared with the PRISM data for 56 years, stage IV (5) has fewer than 10 years with data recorded on more than $90 \%$ of days in each season. It is used here to address the uncertainty expected in daily precipitation due to scale mismatch (Fig. 11). Precipitation over WGEW is representative of winter precipitation over larger areas than it is for summer precipitation in terms of $R$ and NRMSD. For example, stage IV winter precipitation at $2.5^{\circ}$ resolution is represented as well as summer precipitation at $0.75^{\circ}$ resolution. Correlation with daily WGEW precipitation drops off steadily to 0.92 for winter and 0.78 for summer and annual at $2.5^{\circ}$ resolution.

To quantify the scaling mismatch from a pixel to various resolutions, a single stage IV pixel at the center of WGEW is first compared with the average of all pixels within WGEW. The resulting $R$, bias, NRMSD, and $\sigma_{N}$ are $0.91,-0.10 \mathrm{~mm}_{\text {day }}{ }^{-1}, 1.66 \mathrm{~mm} \mathrm{day}^{-1}$, and 0.76 , respectively. Figure S3 in the supplemental material shows that the uncertainty in scaling up from a single pixel to various resolutions is much larger than that using the area average over WGEW. This conclusion is also confirmed using individual gauge observations (Fig. S4 in the supplemental material). For example, the correlation and NRMSD of daily precipitation at individual gauges within WGEW with Pobs ranges from 0.70 to 0.89 and from 1.21 to $2.45 \mathrm{~mm} \mathrm{day}^{-1}$, respectively. This scaling sensitivity from point (or pixel) to the WGEW area is due to the small-scale spatial heterogeneity in precipitation, particularly in convective precipitation that dominates in the wet season in southern Arizona. This is also consistent with the finding of Stillman et al. (2014) that daily precipitation at gauges separated by only $10 \mathrm{~km}$ within WGEW are poorly correlated $(R \sim 0.25)$.

All nonmodeled daily precipitation products have resolutions finer than $0.75^{\circ}$. At $0.75^{\circ}$, stage IV daily precipitation has winter, summer, and annual $R$ of 0.94 , 0.87 , and 0.90 ; bias of $0.18,0.05$, and $0.068 \mathrm{~mm} \mathrm{day}^{-1}$; and NRMSD of $0.69,1.85$, and $1.14 \mathrm{~mm} \mathrm{day}^{-1}$ (Fig. 11). 
These results in Fig. 11 indicate that the impact of scale mismatch on the results in Fig. 3 is relatively small.

\section{Conclusions}

Precipitation drives terrestrial hydrological processes and is an indicator of climate change. Because of its importance, many products have been developed to monitor and predict precipitation. An evaluation of 22 of the most current global and continental gauge-based, satellite, model, and reanalysis precipitation products has been done in this study using daily precipitation measurements from a dense rain gauge network (Pobs) over a long time period (from 1956 to 2013) over WGEW, a $150 \mathrm{~km}^{2}$ watershed located in southeastern Arizona.

Most gauge-based, satellite, and reanalysis products estimate the annual cycle of precipitation very well while one gauge-based product and one satellite product overestimate warm season precipitation and models overestimate cold season precipitation. Most models also show a monsoon season that is shifted forward or backward by a month from the observed July-September period.

The median annual precipitation biases of the gaugebased, satellite, and reanalysis products are nearly within the uncertainty associated with scale mismatch. All nonmodel products are significantly correlated $(p<0.01)$ with Pobs, and the median correlations of gauge-based, satellite, and reanalysis annual precipitation with Pobs are $0.83,0.46$, and 0.68 , respectively. Most products perform better in the winter (with higher $R$ values and lower NRMSDs) than in the summer. Overall, CMIP5 results are the worst. For instance, only one model has annual precipitation that is significantly correlated with Pobs.

Even on daily time scales, all nonmodel products have significant correlations $(p<0.01)$ with Pobs, with median values of $0.54,0.39$, and 0.49 for gauge-based, satellite, and reanalysis products, respectively. All nonmodel products have NRMSDs that are 3-5 times the average daily Pobs of $0.81 \mathrm{~mm} \mathrm{day}^{-1}$. From year to year, $R$ and NRMSD are highly variable for all nonmodel products. For example, CPC (1) has a significant decreasing trend in $R$ with its highest values $>0.8$ and lowest values near 0.2. Model results are the worst among different categories of products, and even their relatively good $\sigma_{N}^{\text {annual }}$ values (i.e., close to 1 ) are due to their compensating overestimate (underestimate) of day-to-day variability of DJF (JJA) precipitation.

Most models overestimate the frequency of drizzle $\left(0.1-3 \mathrm{~mm} \mathrm{day}^{-1}\right)$ and underestimate the frequency of negligible precipitation $\left(<0.1 \mathrm{~mm} \mathrm{day}^{-1}\right)$. In contrast, nonmodel products and Pobs show similar frequency of precipitation in intensity bins. On the other hand, some models do a better job than some of the satellite and reanalysis products at estimating the amount of precipitation that comes from each intensity range.

Of the 17 precipitation products with at least 20 years of data, most agree with Pobs without significant trends. Only HadGEM2-ES (10), ERA-Interim (19), and JRA55 (21) show trends that are not observed by Pobs.

Soil moisture regulates the surface moisture and energy balances, influences local vegetation, and is particularly important in moisture-limited regions such as the WGEW. It is driven by precipitation, but is also influenced by soil properties and atmospheric conditions. Therefore, besides precipitation, we have also evaluated 23 global and continental soil moisture products from various sources in this study using a high-resolution soil moisture product over WGEW (SM). SM is a 58-yr daily soil moisture product for July-September from 1956 to 2013.

The soil moisture products are split into four categories: satellite, model, reanalysis, and LDAS. Most products are biased wet compared with SM, with the smallest median bias associated with satellites $\left(0.0056 \mathrm{~m}^{3} \mathrm{~m}^{-3}\right)$. All other categories have median values greater than $0.1 \mathrm{~m}^{3} \mathrm{~m}^{-3}$. Satellite products also have the lowest median NRMSD of $0.0070 \mathrm{~m}^{3} \mathrm{~m}^{-3}$ followed by LDAS $\left(0.011 \mathrm{~m}^{3} \mathrm{~m}^{-3}\right)$, and reanalysis $\left(0.014 \mathrm{~m}^{3} \mathrm{~m}^{-3}\right)$. CMIP5 results of NRMSD are much worse $\left(0.029 \mathrm{~m}^{3} \mathrm{~m}^{-3}\right)$.

The six satellite products and six of the reanalysis products include daily soil moisture. Satellite products outperform reanalyses with higher $R$ and lower mean biases. With the exception of satellite products $2-4$ and ERA-Interim/Land (19), all products have variability of daily soil moisture close to that of SM. Overall, AMSRE LPRM (3) and TRMM LPRM (4) have the best performance.

From year to year, daily $R$ is highly variable, particularly in ERA-40 (17) and ERA-Interim (18), which range from insignificant to 0.8 . This variability is not improved by the use of the GPCP precipitation in ERAInterim/Land (19). While there are no significant $R$ trends in daily soil moisture from SM, many of the reanalysis products show a peak around 2005 and a minimum in the late 1990s.

The median of each product's daily soil moisture values estimated simultaneously with SM in 0.01 increments for all overlapping days has a significant $(p<$ 0.01 ) and positive correlation with SM. Several of the reanalysis products are more sensitive to variations in soil moisture in very dry conditions than in wetter soils. Among the six satellite products, Aquarius (1) and ASCAT (6) show the best performance. SMOS (5) systematically overestimates soil moisture, while AMSR-E (2) has a very small range of soil moisture, and AMSR-E LPRM (3) and TRMM LPRM (4) are more sensitive to changes in soil moisture in drier soils. 
Of the 17 soil moisture products with at least 20 years of data, most agree with SM without significant trends. Only MIROC5 (8) and ERA-40 (17) show trends that are not observed by SM.

Pobs and SM datasets upscale point measurements to the area of WGEW. However, WGEW is still smaller than the grid size of most products in this study. The uncertainties associated with this scale mismatch have been quantified for grid size from $0.25^{\circ}$ to $2.5^{\circ}$ using the 4-km PRISM (4) and stage IV (5) precipitation products. While the uncertainties due to this scale mismatch usually increase with the grid size from $0.25^{\circ}$ to $1.5^{\circ}$, their impact on daily and annual time scales is overall small. In contrast, the scaling uncertainty from individual gauge or pixel data to various grid sizes would be much larger.

The comprehensive precipitation and soil moisture product evaluations in this study have implications for precipitation and soil moisture product development and evaluations. For product development, various strengths and weaknesses have been identified for future improvement. For instance, CPC (1) daily gauge-radar precipitation product degrades steadily from 1956 to 2013 with decreasing $R$ and increasing RMSD compared with Pobs. SMOS (5) overestimates soil moisture. JRA55 (21) precipitation shows a spurious trend of $64.13 \mathrm{~mm} \mathrm{decade}^{-1}(p<0.01)$ for annual precipitation, which is mostly manifested in a sharp (and spurious) increase of annual precipitation amount from $<300 \mathrm{~mm}$ in 1975 to $>900 \mathrm{~mm}$ in 1983 .

As categories, gauge-radar precipitation and satellite precipitation and soil moisture products perform best, followed by reanalysis products, and model results are the worst. On the other hand, individual gauge-radar and satellite products are not necessarily better than some reanalysis products, and they are occasionally even not as good as model results in some performance metrics. For instance, the JJA precipitation bias from PERSIANN (8) satellite-only product is highest among all products (including models). Therefore, for reanalysis product evaluations, several gauge-radar and satellite products along with their uncertainties should be used. Similarly, for model evaluations, multiple nonmodel products along with their uncertainties should be used.

Acknowledgments. This work was supported by NSF (EF1238908 and AGS-0944101) and NASA (NNX14AM02G). Two anonymous reviewers are thanked for helpful comments that significantly increased the clarity of our presentation. The USDA-ARS Southwest Watershed Research Center is thanked for providing long-term, high-quality precipitation and soil moisture data used in this study (available at http://www.tucson.ars.ag.gov/ dap/). Several of the datasets used in this analysis were

obtained from the following archives: NCAR Computational and Information Systems Laboratory; Barcelona Expert Center; DOE Program for Climate Model Diagnosis and Intercomparison; University of California, Irvine, Center for Hydrometeorology and Remote Sensing; NOAA Earth System Research Laboratory; NCAR Earth Observing Laboratory; National Snow and Ice Data Center; NASA Goddard Earth Sciences Data and Information Services Center; and Earth Online. We would like to acknowledge the archive developers for providing high-quality data that made this work possible. Additionally, we appreciate ECMWF and NASA for providing nicely formatted data for public use.

\section{APPENDIX}

\section{List of Acronyms}

AIRS

AMSR-E

AMSU-B

ASCAT

AR5

BGC

CAM5

CAMS

CCSM

CDEC

CESM

CFSR

CMAP

CMIP

CMORPH

COOP

$\mathrm{CPC}$

DMSP

EC

ECMWF

ERA

GFDL

GFDL CM3

GHCN

GLDAS

GMS

GOES

GPCC

GPCP

GPI
Atmospheric Infrared Sounder

Advanced Microwave Scanning Radiometer for Earth Observing System Advanced Microwave Sounding Unit-B

Advanced Scatterometer

Fifth Assessment Report

Biogeochemical

Community Atmosphere Model, version 5

Climate Anomaly Monitoring System

Community Climate System Model

California Data Exchange Center

Community Earth System Model

Climate Forecast System Reanalysis

CPC Merged Analysis of Precipitation

Coupled Model Intercomparison Project

CPC morphing technique

Cooperative Observer

Climate Prediction Center

Defense Meteorological Satellite Program

Environment Canada

European Centre for Medium-Range Weather Forecasts

ECMWF Re-Analysis

Geophysical Fluid Dynamics Laboratory

GFDL Climate Model, version 3

Global Historical Climatology Network

Global Land Data Assimilation System

Geostationary Meteorological Satellite

Geostationary Operational Environmental Satellite

Global Precipitation Climatology Centre

Global Precipitation Climatology Project

GOES precipitation index 


\section{GTS \\ HadCM3 \\ HadGEM2- ES \\ HADS}

IPCC

IR

IQR

JRA-55

LDAS

LPRM

MERRA

MIROC5

NARR

NLDAS

OPI

PERSIANN Precipitation Estimation from Remotely Sensed Information Using Artificial Neural Networks

PREC/L PRISM

RAWS

RFC

RFI

SMAP

SMEX04

SMOS

SNOTEL

$\mathrm{SSM} / \mathrm{I}$

TOVS

TMI

TRMM

USDA-

ARS

VUA

WGEW

WMO

Global Telecommunication System

Hadley Centre Coupled Model, version 3

Hadley Centre Global Environment

Model, version 2-Earth System

Hydrometeorological Automated Data System

Intergovernmental Panel on Climate Change

Infrared

Interquartile range (75th percentile minus 25 th percentile)

Japanese 55-year Reanalysis Project

Land Data Assimilation System

Land Parameter Retrieval Model

Modern-Era Retrospective Analysis for Research and Applications

Model for Interdisciplinary Research on Climate, version 5

North American Regional Reanalysis

North American Land Data Assimilation System

Outgoing Longwave Radiation (OLR)

Precipitation Index

Precipitation Reconstruction over Land

Parameter-Elevation Regressions on Independent Slopes Model

Remote Automatic Weather Stations

River Forecast Center

Radio-frequency interference

Soil Moisture Active Passive

Soil Moisture Experiment 2004

Soil Moisture Ocean Salinity

Snowpack Telemetry

Special Sensor Microwave Imager

Television Infrared Observation Satellite (TIROS) Operational Vertical Sounder

TRMM Microwave Imager

Tropical Rainfall Measuring Mission

U.S. Department of Agriculture-

Agricultural Research Service

Vrije Universiteit Amsterdam

Walnut Gulch Experimental Watershed

World Meteorological Organization

\section{REFERENCES}

Amitai, E., C. L. Unkrich, D. C. Goodrich, E. Habib, and B. Thill, 2012: Assessing satellite-based rainfall estimates in semiarid watersheds using the USDA-ARS Walnut Gulch gauge

network and TRMM PR. J. Hydrometeor., 13, 1579-1588, doi:10.1175/JHM-D-12-016.1.

Balsamo, G., and Coauthors, 2015: ERA-Interim/Land: A global land surface reanalysis data set. Hydrol. Earth Syst. Sci., 19, 389-407, doi:10.5194/hess-19-389-2015.

Bartalis, Z., W. Wagner, V. Naeimi, S. Hasenauer, K. Scipal, H. Bonekamp, J. Figa, and C. Anderson, 2007: Initial soil moisture retrievals from the MetOp-A Advanced Scatterometer (ASCAT). Geophys. Res. Lett., 34, L20401, doi:10.1029/ 2007 GL031088.

Becker, A., P. Finger, A. Meyer-Christoffer, B. Rudolf, K. Schamm, U. Schneider, and M. Ziese, 2013: A description of the global land-surface precipitation data products of the Global Precipitation Climatology Centre with sampling applications including centennial trend analysis from 1901-present. Earth Syst. Sci. Data, 5, 71-99, doi:10.5194/essd-5-71-2013.

Bitew, M. M., M. Gebremichael, L. T. Ghebremichael, and Y. A. Bayissa, 2012: Evaluation of high-resolution satellite rainfall products through streamflow simulation in a hydrological modeling of a small mountainous watershed in Ethiopia. J. Hydrometeor., 13, 338-350, doi:10.1175/2011JHM1292.1.

Bosilovich, M. G., 2013: Regional climate and variability of NASA MERRA and recent reanalyses: U.S. summertime precipitation and temperature. J. Appl. Meteor. Climatol., 52, 1939-1951, doi:10.1175/JAMC-D-12-0291.1.

_ , J. Chen, F. R. Robertson, and R. F. Adler, 2008: Evaluation of global precipitation in reanalyses. J. Appl. Meteor. Climatol., 47, 2279-2299, doi:10.1175/2008JAMC1921.1.

Chang, M., and L. A. Flannery, 1998: Evaluating the accuracy of rainfall catch by three different gauges. J. Amer. Water Resour. Assoc., 34, 559-564, doi:10.1111/j.1752-1688.1998.tb00954.x.

Chen, M., R. E. Dickinson, X. Zeng, and A. Hahmann, 1996: Comparison of precipitation observed over the continental United States to that simulated by a climate model. J. Climate, 9, 22332249, doi:10.1175/1520-0442(1996)009<2233:COPOOT>2.0.CO;2.

Chen, M., P. Xie, J. E. Janowiak, and P. A. Arkin, 2002: Global land precipitation: A 50-yr monthly analysis based on gauge observations. J. Hydrometeor., 3, 249-266, doi:10.1175/ 1525-7541(2002)003<0249:GLPAYM>2.0.CO;2.

Corbosiero, K. L., M. J. Dickinson, and L. F. Bosart, 2009: The contribution of eastern North Pacific tropical cyclones to the rainfall climatology of the southwest United States. Mon. Wea. Rev., 137, 2415-2435, doi:10.1175/2009MWR2768.1.

Cosgrove, B. A., and Coauthors, 2003: Real-time and retrospective forcing in the North American Land Data Assimilation System (NLDAS) project. J. Geophys. Res., 108, 8842, doi:10.1029/ 2002JD003118.

Crow, W. T., and Coauthors, 2012: Upscaling sparse ground-based soil moisture observations for the validation of coarseresolution satellite soil moisture products. Rev. Geophys., $\mathbf{5 0}$, RG2002, doi:10.1029/2011RG000372.

Daly, C., R. P. Neilson, and D. L. Phillips, 1994: A statisticaltopographic model for mapping climatological precipitation over mountainous terrain. J. Appl. Meteor., 33, 140-158, doi:10.1175/1520-0450(1994)033<0140:ASTMFM>2.0.CO;2.

Decker, M., M. A. Brunke, Z. Wang, K. Sakaguchi, X. Zeng, and M. G. Bosilovich, 2012: Evaluation of the reanalysis products from GSFC, NCEP, and ECMWF using flux tower observations. J. Climate, 25, 1916-1944, doi:10.1175/JCLI-D-11-00004.1.

Dee, D. P., and Coauthors, 2011: The ERA-Interim reanalysis: Configuration and performance of the data assimilation system. Quart. J. Roy. Meteor. Soc., 137, 553-597, doi:10.1002/ qj.828. 
de Jeu, R. A. M., W. W. Wagner, T. R. H. Holmes, A. J. Dolman, N. C. van de Giesen, and J. Friesen, 2008: Global soil moisture patterns observed by space borne microwave radiometers and scatterometers. Surv. Geophys., 29, 399-420, doi:10.1007/ s10712-008-9044-0.

Devine, K., and E. Mekis, 2008: Field accuracy of Canadian rain measurements. Atmos.-Ocean, 46, 213-227, doi:10.3137/ ao.460202.

Donner, L. J., and Coauthors, 2011: The dynamical core, physical parameterizations, and basic simulation characteristics of the atmospheric component AM3 of the GFDL Global Coupled Model CM3. J. Climate, 24, 3484-3519, doi:10.1175/ 2011JCLI3955.1.

Ebita, A., and Coauthors, 2011: The Japanese 55-year Reanalysis "JRA-55": An interim report. SOLA, 7, 149-152, doi:10.2151/ sola.2011-038.

Entekhabi, D., and Coauthors, 2010: The Soil Moisture Active and Passive (SMAP) Mission. Proc. IEEE, 98, 704-716, doi:10.1109/JPROC.2010.2043918.

Gao, Y. C., and M. F. Liu, 2013: Evaluation of high-resolution satellite precipitation products using rain gauge observations over the Tibetan Plateau. Hydrol. Earth Syst. Sci., 17, 837-849, doi:10.5194/hess-17-837-2013.

Geil, K. L., Y. L. Serra, and X. Zeng, 2013: Assessment of CMIP5 model simulations of the North American monsoon system. J. Climate, 26, 8787-8801, doi:10.1175/JCLI-D-13-00044.1.

Gent, P. R., and Coauthors, 2011: The Community Climate System Model version 4. J. Climate, 24, 4973-4991, doi:10.1175/ 2011JCLI4083.1.

Goodrich, D. C., T. O. Keefer, C. L. Unkrich, M. H. Nichols, H. B. Osborn, J. J. Stone, and J. R. Smith, 2008: Long-term precipitation database, Walnut Gulch Experimental Watershed, Arizona, United States. Water Resour. Res., 44, W05S04, doi:10.1029/2006WR005782.

Habib, E., W. F. Krajewski, V. Nespor, and A. Kruger, 1999: Numerical simulation studies of rain gauge data correction due to wind effect. J. Geophys. Res., 104, 19723-19733, doi:10.1029/ 1999JD900228.

Higgins, R. W., W. Shi, E. Yarosh, and R. Joyce, 2000: Improved United States precipitation quality control system and analysis. NCEP/CPC Atlas 7, $40 \mathrm{pp}$

Huffman, G. J., R. F. Adler, M. Morrissey, D. T. Bolvin, S. Curtis, R. Joyce, B. McGavock, and J. Susskind, 2001: Global precipitation at one-degree daily resolution from multisatellite observations. J. Hydrometeor., 2, 36-50, doi:10.1175/ 1525-7541(2001)002<0036:GPAODD > 2.0.CO;2.

— , and Coauthors, 2007: The TRMM Multisatellite Precipitation Analysis (TMPA): Quasi-global, multiyear, combined-sensor precipitation estimates at fine scales. J. Hydrometeor., 8, 38-55, doi:10.1175/JHM560.1.

Jackson, T., D. Le Vine, A. Griffis, D. Goodrich, T. Schmugge, C. Swift, and P. O'Neill, 1993: Soil moisture and rainfall estimation over a semiarid environment with the ESTAR microwave radiometer. IEEE Trans. Geosci. Remote Sens., 31, 836-841, doi:10.1109/36.239906.

Jiang, S., L. Ren, Y. Hong, B. Yong, X. Yang, F. Yuan, and M. Ma, 2012: Comprehensive evaluation of multi-satellite precipitation products with a dense rain gauge network and optimally merging their simulated hydrological flows using the Bayesian model averaging method. J. Hydrol., 452-453, 213225, doi:10.1016/j.jhydrol.2012.05.055.

Johns, T. C., and Coauthors, 2003: Anthropogenic climate change for 1860 to 2100 simulated with the HadCM3 model under updated emissions scenarios. Climate Dyn., 20, 583-612, doi:10.1007/s00382-002-0296-y.

Jones, C. D., and Coauthors, 2011: The HadGEM2-ES implementation of CMIP5 centennial simulations. Geosci. Model Dev., 4, 543-570, doi:10.5194/gmd-4-543-2011.

Joyce, R. J., J. E. Janowiak, P. A. Arkin, and P. Xie, 2004: CMORPH: A method that produces global precipitation estimates from passive microwave and infrared data at high spatial and temporal resolution. J. Hydrometeor., 5, 487-503, doi:10.1175/1525-7541(2004)005<0487:CAMTPG >2.0.CO;2.

Keefer, T. O., M. S. Moran, and G. B. Paige, 2008: Long-term meteorological and soil hydrology database, Walnut Gulch Experimental Watershed, Arizona, United States. Water Resour. Res., 44, W05S07, doi:10.1029/2006WR005702.

Kerr, Y. H., P. Waldteufel, J.-P. Wigneron, J.-M. Martinuzzi, J. Font, and M. Berger, 2001: Soil moisture retrieval from space: The Soil Moisture and Ocean Salinity (SMOS) mission. IEEE Trans. Geosci. Remote Sens., 39, 1729-1735, doi:10.1109/ 36.942551.

Lamarque, J.-F., and Coauthors, 2012: CAM-chem: Description and evaluation of interactive atmospheric chemistry in the Community Earth System Model. Geosci. Model Dev., 5, 369411, doi:10.5194/gmd-5-369-2012.

Legates, D. R., and C. J. Willmott, 1990: Mean seasonal and spatial variability in gauge-corrected, global precipitation. J. Climate, 10, 111-127, doi:10.1002/joc.3370100202.

Le Vine, D. M., G. S. E. Lagerloef, R. Colomb, S. Yueh, and F. Pellerano, 2007: Aquarius: An instrument to monitor sea surface salinity from space. IEEE Trans. Geosci. Remote Sens., 45, 2040-2050, doi:10.1109/TGRS.2007.898092.

Lin, Y., and K. E. Mitchell, 2005: The NCEP stage II/IV hourly precipitation analyses: Development and applications. Preprints, 19th Conf. on Hydrology, San Diego, CA, Amer. Meteor. Soc., 1.2. [Available online at https://ams.confex.com/ ams/Annual2005/techprogram/paper_83847.htm.]

Liu, J., A. Zhu, and Z. Duan, 2012: Evaluation of TRMM 3B42 precipitation product using rain gauge data in Meichuan watershed, Poyang Lake basin, China. J. Resour. Ecol., 3, 359366, doi:10.5814/j.issn.1674-764x.2012.04.009.

Liu, X., and Coauthors, 2012: Toward a minimal representation of aerosols in climate models: description and evaluation in the Community Atmosphere Model CAM5. Geosci. Model Dev., 5, 709-739, doi:10.5194/gmd-5-709-2012.

Matsuura, K., and C. J. Willmott, 2012: Terrestrial precipitation: 1900-2010 Gridded monthly time series (version 3.01). Accessed 20 August 2015. [Available online at http://climate. geog.udel.edu/ climate/html_pages/Global2011/README. GlobalTsP2011.html.]

Mesinger, F., and Coauthors, 2006: North American Regional Reanalysis. Bull. Amer. Meteor. Soc., 87, 343-360, doi:10.1175/ BAMS-87-3-343.

Moore, J. K., K. Lindsay, S. C. Doney, M. C. Long, and K. Misumi, 2013: Marine Ecosystem Dynamics and Biogeochemical Cycling in the Community Earth System Model [CESM1(BGC)]: Comparison of the 1990s with the 2090s under the RCP4.5 and RCP8.5 scenarios. J. Climate, 26, 9291-9312, doi:10.1175/ JCLI-D-12-00566.1.

Njoku, E. G., T. L. Jackson, V. Lakshm, T. Chan, and S. V. Nghiem, 2003: Soil moisture retrieval from AMSR-E. IEEE Trans. Geosci. Remote Sens., 41, 215-229, doi:10.1109/ TGRS.2002.808243.

Owe, M., R. A. M. de Jeu, and T. R. H. Holmes, 2008: Multisensor historical climatology of satellite-derived global land surface 
moisture. J. Geophys. Res., 113, F01002, doi:10.1029/ 2007JF000769.

Parinussa, R. M., T. R. H. Holmes, N. Wanders, W. A. Dorigo, and R. A. M. de Jeu, 2015: A preliminary study toward consistent soil moisture from AMSR2. J. Hydrometeor., 16, 932-947, doi:10.1175/JHM-D-13-0200.1.

Reichle, R. H., R. D. Koster, G. J. M. De Lannoy, B. A. Forman, Q. Liu, S. P. P. Mahanama, and A. Touré, 2011: Assessment and enhancement of MERRA land surface hydrology estimates. J. Climate, 24, 6322-6338, doi:10.1175/JCLI-D-10-05033.1.

Rienecker, M. M., and Coauthors, 2011: MERRA: NASA's ModernEra Retrospective Analysis for Research and Applications. J. Climate, 24, 3624-3648, doi:10.1175/JCLI-D-11-00015.1.

Rodell, M., and Coauthors, 2004: The Global Land Data Assimilation System. Bull. Amer. Meteor. Soc., 85, 381-394, doi:10.1175/ BAMS-85-3-381.

Ryu, D., T. J. Jackson, R. Bindlish, D. M. Le Vine, and M. Haken, 2010: Soil moisture retrieval using a two-dimensional L-band synthetic aperture radiometer in a semiarid environment. IEEE Trans. Geosci. Remote Sens., 48, 4273-4284, doi:10.1109/ TGRS.2010.2051677.

Saha, S., and Coauthors, 2010: The NCEP Climate Forecast System Reanalysis. Bull. Amer. Meteor. Soc., 91, 1015-1057, doi:10.1175/2010BAMS3001.1.

Schmugge, T. J., and T. J. Jackson, 1994: Mapping soil moisture with microwave radiometers. Meteor. Atmos. Phys., 54, 213 223, doi:10.1007/BF01030061.

Sheffield, J., and Coauthors, 2013: North American climate in CMIP5 experiments. Part II: Evaluation of historical simulations of intraseasonal to decadal variability. J. Climate, 26, 9247-9290, doi:10.1175/JCLI-D-12-00593.1.

Sillmann, J., V. V. Kharin, X. Zhang, F. W. Zwiers, and D. Bronaugh, 2013: Climate extremes indices in the CMIP5 multimodel ensemble: Part 1. Model evaluation in the present climate. J. Geophys. Res. Atmos., 118, 1716-1733, doi:10.1002/ jgrd.50203.

Sorooshian, S., K. Hsu, X. Gao, H. V. Gupta, B. Imam, and D. Braithwaite, 2000: Evaluation of PERSIANN system satellite-based estimates of tropical rainfall. Bull. Amer. Meteor Soc., 81, 2035-2046, doi:10.1175/1520-0477(2000)081<2035: EOPSSE $>2.3 . \mathrm{CO} ; 2$.

Stampoulis, D., and E. N. Anagnostou, 2012: Evaluation of global satellite rainfall products over continental Europe. J. Hydrometeor., 13, 588-603, doi:10.1175/JHM-D-11-086.1.

Stillman, S., X. Zeng, W. J. Shuttleworth, D. C. Goodrich, C. L. Unkrich, and M. Zreda, 2013: Spatiotemporal variability of summer precipitation in southeastern Arizona. J. Hydrometeor., 14, 1944-1951, doi:10.1175/JHM-D-13-017.1.

_, J. Ninneman, X. Zeng, T. Franz, R. L. Scott, W. J. Shuttleworth, and K. Cummins, 2014: Summer soil moisture spatiotemporal variability in southeastern Arizona. J. Hydrometeor. 15, 1473-1485, doi:10.1175/JHM-D-13-0173.1.

Torres, R., and Coauthors, 2012: GMES Sentinel-1 mission. Remote Sens. Environ., 120, 9-24, doi:10.1016/j.rse.2011.05.028.

Uppala, S. M., and Coauthors, 2005: The ERA-40 Re-Analysis. Quart. J. Roy. Meteor. Soc., 131, 2961-3012, doi:10.1256/ qj.04.176.

Ventura, F., O. Facini, S. Piana, and R. Pisa Paola, 2010: Soil moisture measurements: Comparison of instrumentation performances. J. Irrig. Drain. Div., 136, 81-89, doi:10.1061/ (ASCE)0733-9437(2010)136:2(81).

Watanabe, M., and Coauthors, 2010: Improved climate simulation by MIROC5: Mean states, variability, and climate sensitivity. J. Climate, 23, 6312-6335, doi:10.1175/2010JCLI3679.1.

Zreda, M., W. J. Shuttleworth, X. Zeng, C. Zweck, D. Desilets, T. Franz, and R. Rosolem, 2012: COSMOS: The Cosmic-Ray Soil Moisture Observing System. Hydrol. Earth Syst. Sci., 16, 4079-4099, doi:10.5194/hess-16-4079-2012. 